Check for updates

Cite this: RSC Adv., 2017, 7, 46745

Received 3rd March 2017

Accepted 19th September 2017

DOI: $10.1039 / c 7 r a 02612 a$

rsc.li/rsc-advances

\section{Complete genome sequencing of Arachidicoccus ginsenosidimutans sp. nov., and its application for production of minor ginsenosides by finding a novel ginsenoside-transforming $\beta$-glucosidase $\dagger$}

\begin{abstract}
Muhammad Zubair Siddiqi, ${ }^{* a b}$ Siddiqi Muhammad Shafic and Wan-Taek Im (iD *ab
A novel bacterial strain $\left(B S 20^{\top}\right)$, which has ginsenoside-transforming ability, was whole genome sequenced for the identification of a target gene. After complete genome sequencing, phylogenetic, phenotypic and chemotaxonomic analyses, the strain $\mathrm{BS}^{2} \mathrm{O}^{\top}$ (Arachidicoccus ginsenosidimutans sp. nov.) was placed within the genus Arachidicoccus of family Chitinophagaceae. The complete genome of strain $\mathrm{BS}^{2} \mathrm{O}^{\top}$ comprised a circular chromosome of $4138017 \mathrm{bp}$. To find the target functional gene, 17 sets of four different glycoside hydrolases were cloned in E. coli BL21 (DE3) using the pGEX4T-1 vector and were characterized. Among these 17 sets of clones, only one, BglAg-762, exhibited ginsenoside-conversion ability. The BglAg-762 comprised 762 amino acid residues and belonged to the glycoside hydrolase family 3. The recombinant enzyme (GST-BglAg762) was able to convert major ginsenosides $\mathrm{Rb}_{1}$ to $\mathrm{F}_{2}$ via gypenoside-XVII (Gyp-XVII), $\mathrm{Rb}_{2}$ to $\mathrm{C}-\mathrm{O}$, and $\mathrm{Rb}_{3}, \mathrm{Rc}, \mathrm{Rd}$, and $\mathrm{Gyp}-\mathrm{XVII}$ to $\mathrm{C}-\mathrm{Mx_{1 }}, \mathrm{C}-\mathrm{Mc}_{1}$, and $\mathrm{F}_{2}$, respectively. Finally, ginsenoside $\mathrm{F}_{2}$ was transformed into compound $\mathrm{K}(\mathrm{C}-\mathrm{K})$. Besides, these pilot data demonstrate the identification of 17 sets of target/functional genes of 4 different glycoside hydrolases from a novel bacterial species via whole genome sequencing. Our results have shown that the recombinant BglAg-762 very quickly converts the major ginsenosides into minor ginsenosides, which can be used for the enhanced production of target minor ginsenosides. Furthermore, the web service of NCBI is suitable for any targeted gene identification, but based on our experimental analysis we concluded that the hypothetical protein present in NCBI should be considered as a putative or uncharacterized protein.
\end{abstract}

\section{Introduction}

Ginseng, the root of Panax ginseng C. A. Meyer, which has been used as herbal medicine in Asian countries (China, Korea, and Japan) for centuries, has gained fame in western countries in recent decades. ${ }^{1-3}$ The pharmacological active ingredients in ginseng have been reported to be ginsenosides, a class of distinctive triterpene glucosides. ${ }^{\mathbf{4} \mathbf{6}}$ Based on differences in chemical constitution and dammarane skeleton, ginsenosides are categorized as protopanaxadiol (PPD), protopanaxatriol

\footnotetext{
${ }^{a}$ Department of Biotechnology, Hankyong National University, 327 Chungang-no, Anseong-si, Kyonggi-do 17579, Republic of Korea. E-mail: mzsiddiqi1988@yahoo. com; wandra@hknu.ac.kr; Fax: +82-31-670-5339; Tel: +82-31-670-5335

${ }^{b}$ Center for Genetic Information, Graduate School of Bio and Information Technology, Hankyong National University, 327 Chungang-no, Anseong-si, Kyonggi-do 17579, Republic of Korea

${ }^{c}$ Green Planet Co. Ltd, Tsushima nishizaka 2 chome 5-41-203, Okayama, Okayama ken, Japan
}

$\dagger$ Electronic supplementary information (ESI) available. See DOI: 10.1039/c7ra02612a
(PPT), and oleanane-type saponins. ${ }^{6}$ Major ginsenosides are natural high molecular-weight glycosides of triterpene; due to their size, low solubility, and poor permeability through the cell membrane, they are not easily absorbed by the human gastrointestinal system. ${ }^{7,8}$ It was reported previously that major ginsenosides $\left(R b_{1}, R b_{2}, R c\right.$, and $\left.R d\right)$, when taken orally, are converted into minor ginsenosides $\left(\mathrm{Rg}_{3}, \mathrm{Rh}_{2}, \mathrm{~F}_{2}\right.$, and compound $\mathrm{K}[\mathrm{CK}]$ ) by intestinal bacteria. ${ }^{9}$ Many studies have been performed to investigate the conversion of major ginsenosides into minor ginsenosides, which possess desirable pharmaceutical activities and can be readily absorbed by the human body. So far, researchers have used heat treatment, chemical treatment (acid or base), microorganisms and highlyexpressed recombinant glycoside hydrolase enzymes for converting major ginsenosides into minor ginsenosides for exploiting their pharmacological and cosmetic applications. ${ }^{\mathbf{1 0 - 1 4}}$ Therefore, studies have been mainly focused on finding suitable microbes or enzymes to transform major ginsenosides into minor ginsenosides. Minor ginsenosides are derivatives of major ginsenosides, exist in smaller amounts in the total 
ginseng ginsenosides, and show desirable pharmacological effects such as anti-cancer, anti-oxidative, anti-diabetic, antiaging, and anti-osteoporosis. ${ }^{15-22}$ Therefore, the initial biotransformation of PPD- or PPT-type ginsenosides is very important. Thus, for primary bioconversion of ginsenosides, 11 novel species were screened, as shown in Fig. S1. $\dagger$ After screening, based on the efficiency of bioconversion, strain $B S 20^{T}$ was selected for complete genome sequencing to find the target functional gene. The novel strain $\mathrm{BS}^{2} \mathrm{O}^{\mathrm{T}}$ was taxonomically characterized, and was found to belong to the genus Arachidicoccus.

The genus Arachidicoccus was recently described by Madhaiyan et al. (2015) based on the description of a single species. Phylogenetically, the genus belongs to the phylum Bacteroidetes and is closely related to members of the family Chitinophagaceae. At the time of writing, the genus Arachidicoccus comprises only two recognized species, A. rhizosphaerae KCTC $22378^{\mathrm{T}}$ and A. ginsenosidivorans KCTC $22820^{\mathrm{T}}$ (http://www.bacterio.net). Both members of this genus are Gram-negative, non-motile, non-flagellated, and non-spore forming. ${ }^{22,23}$ Affiliates of this genus are negative for flexirubin-type reactions. The major quinone found in members of this genus was menaquinone MK-7 and the main polar lipid, phosphatidylethanolamine (PE). The described species of the genus contained iso- $\mathrm{C}_{15: 0}$, iso- $\mathrm{C}_{15: 1}$ $\mathrm{G}$, iso- $\mathrm{C}_{17: 0} 3-\mathrm{OH}$, and summed feature 3 (comprising $\mathrm{C}_{16: 1} \omega 7 \mathrm{c}$ and/or $\mathrm{C}_{16: 1} \omega 6 \mathrm{c}$ ) as the major cellular fatty acids. ${ }^{22,23}$ As the strain $\mathrm{BS}^{\mathrm{T}} \mathrm{T}^{\mathrm{T}}$ showed ginsenoside-conversion ability, it whole genome was sequenced to find the target gene responsible for this conversion.

Today, techniques for whole genome sequencing of bacterial strains are rapidly developing. In bacterial taxonomy, the complete genome sequence is considered the most important source of information for describing a species. In 1995, the first two complete bacterial genomes were sequenced and published. ${ }^{\mathbf{2 4 , 2 5}}$ Thereafter, the study of bacteria has dramatically changed. Using third-generation DNA sequencing, it is possible to identify any gene of interest from the complete genome of a bacterial strain within a few hours along with the complete/ whole genome as well.

In this study, we described the phenotypic and genomic properties of a novel Arachidicoccus strain, A. ginsenosidimutans $\mathrm{BS} 20^{\mathrm{T}}$. As the strain $\mathrm{BS} 20^{\mathrm{T}}$ exhibited efficient conversion of major ginsenosides into minor ginsenosides. Therefore, after the complete genome analysis, 17 sets of 4 different glycoside hydrolases ( $\beta$-glucosidase; $\alpha, \beta$-xylosidase; L-rhamnosidase; and $\alpha, \beta$-arabinofuranosidase) were isolated and cloned in $E$. coli BL21 (DE3). In addition, both the novel species, which was designated as strain $\mathrm{BS}^{2} 0^{\mathrm{T}}$ and the novel recombinant $\beta$-glycosidase (BglAg-762), which belonged to the glycoside hydrolase family 3 , were characterized.

\section{Materials and methods}

\subsection{Chemicals and ginsenoside standards}

The ginsenoside standards, $\mathrm{Rb}_{1}, \mathrm{Rc}, \mathrm{Rb}_{2}, \mathrm{Rb}_{3}, \mathrm{Rd}, \mathrm{Re}, \mathrm{Rg}_{1}$, and Gyp-XVII, were purchased from Nanjing Zelang Medical Technology Co. Ltd. (China). PPD-type ginsenoside mixture extracted from the roots of Panax quinquefolius (American root saponins, mainly comprising $\mathrm{Rb}_{1}$, Rc, and $\mathrm{Rd}$ ) was acquired from Hongjiou Biotech Co. Ltd. (China), and was used as the initial substrate in this study. The $p$-nitrophenyl- $\beta$-D-glucopyranoside ( $p$ NPGlc) and other substrates used in the study were purchased from Sigma.

\subsection{Strain isolation for ginsenoside biotransformation}

During the course of a study to determine the types of aerobic bacteria in compost (made from foodstuff waste), the samples were collected from different places in Daejeon city, South Korea. Then, the samples were thoroughly suspended with $0.85 \%$ saline (sterilized), following serial dilution, and then were spread onto an R2A agar medium (BD). The plates were incubated at $30{ }^{\circ} \mathrm{C}$ for 7 days. Single colony was obtained by subculture. The strain $\mathrm{BS} 20^{\mathrm{T}}$ was seek out, and then it was routinely cultured on $\mathrm{R} 2 \mathrm{~A}$ agar at $30{ }^{\circ} \mathrm{C}$ and preserved as glycerol suspensions $(25 \%, \mathrm{v} / \mathrm{v})$ at $-80{ }^{\circ} \mathrm{C}$.

For screening $\beta$-glucosidase-positive bacteria, the colonies were isolated from different sources, including compost and ginseng soil. To check the $\beta$-glucosidase activities of the novel strains, the isolates were transferred to esculin-R2A agar plates (R2A agar containing $1.0 \mathrm{~g} \mathrm{~L}^{-1}$ esculin and $0.5 \mathrm{~g} \mathrm{~L}^{-1}$ ferric citrate), and incubated at $30{ }^{\circ} \mathrm{C}$ for $1-3$ days. The $\beta$-glucosidase-positive strains, which released esculetin (reddish-brown zone) from esculin, were selected and used for the bioconversion of ginsenosides. Briefly, the liquid R2A broth cultures of these $\beta$-glucosidase-positive bacterial strains in their maximum growth phase were mixed with 200 $\mu \mathrm{L}$ of sterilized $\mathrm{R} 2 \mathrm{~A}$ broth containing $1 \mathrm{mg} \mathrm{mL}^{-1}$ of PPD-mix $\left[\left(\mathrm{Rb}_{1}, \mathrm{Rb}_{2}\right.\right.$, and $\left.\left.\mathrm{Rc}\right)\right]$ or PPT-mix [Re and $\mathrm{Rg}_{1}$ ] type ginsenosides in a $1.5 \mathrm{~mL}$ Eppendorf Tube and incubated at $30^{\circ} \mathrm{C}$ for 24 hours. After 24 hours, $50 \mu \mathrm{L}$ aliquots were taken, extracted with an equal volume of $80 \%$ water-saturated $n$-butanol, and then analyzed by thin layer chromatography [TLC] (Fig. S1 $\dagger$ ). The novel strain $\mathrm{BS}^{\mathrm{T}} \mathrm{O}^{\mathrm{T}}$, which exhibited ginsenosidehydrolyzing activity, was selected for complete genome sequencing and further experiments.

\subsection{Taxonomic characterization of strain $\mathrm{BS}^{\mathrm{T}} \mathrm{T}$ Sp. nov.}

2.3.1. $\mathrm{G}+\mathbf{C}$ content. The $\mathrm{G}+\mathrm{C}$ content $(\mathrm{mol} \%)$ in the DNA of strain $\mathrm{BS}^{2} \mathrm{O}^{\mathrm{T}}$ was estimated from the complete genome sequencing data.

2.3.2. 16S rRNA gene sequence analysis and phylogenetic tree construction. DNA was extracted from strain $\mathrm{BS}_{2} 0^{\mathrm{T}}$ and amplified using PCR; the primers used and the conditions for sequencing the 16S rRNA gene were based on a previous study by Im et al. ${ }^{26}$ Almost full-length sequence of the 16S rRNA gene was assembled using the SeqMan software (DNASTAR). The 16S rRNA gene sequences of related taxa were obtained from the GenBank database and ezbiocloud. ${ }^{27}$ Multiple sequence alignments were performed with the Clustal_X program. ${ }^{28}$ The gaps in the sequence were edited using the BioEdit program, as described by Hall, ${ }^{29}$ and 1450 nucleotides were used for phylogenetic tree construction. For maximum-likelihood tree analysis, evolutionary distances were calculated using the Kimura 
two-parameter model $(\mathrm{K} 2 \mathrm{P})^{30}$ with the NNI (nearest-neighbor interchange) heuristic method, while the NJ (neighborjoining) tree was constructed with the same model (K2P model) and the gaps were edited with complete deletion. ${ }^{31}$ Likewise, a maximum-parsimony tree was created with the SPR (subtree-pruning-regrafting) heuristic method with the gaps of complete deletion using the MEGA6 program with bootstrap values based on 1000 replications. ${ }^{32-34}$

2.3.3. Physiological, biochemical, and chemotaxonomical characteristics. For the phenotypic and biochemical tests, the $\mathrm{BS} 20^{\mathrm{T}}$ strain was routinely cultivated on the R2A agar medium. Gram staining and oxidase, catalase, and hydrolysis of casein, CM-cellulose, DNA, starch, and Tween-80, Tween20 , chitin and tyrosine were determined using the methods of Gerhardt et al. ${ }^{35}$ The morphology of cells grown for 3 days was examined using a scanning electron microscope (Hitachi SU-3500) and a phase-contrast microscope (Nikon, Japan). Cell motility was determined using the hanging drop method. ${ }^{36}$ To investigate the optimal medium for growth, the $\mathrm{BS}^{\mathrm{T}}{ }^{\mathrm{T}}$ strain was cultured on R2A agar (Difco), nutrient agar (NA, Difco), trypticase soy agar (TSA, Difco), Luria-Bertani agar (Difco), and MacConkey agar (Difco), and the plates were incubated for 7 days at $30{ }^{\circ} \mathrm{C}$. Growth at different temperatures $\left(4,10,15,25,30,37\right.$, and $\left.42{ }^{\circ} \mathrm{C}\right)$ and $\mathrm{pH}$ values ( $\mathrm{pH}$ 4-10.0 with intervals of 1.0) was evaluated after incubation in R2A broth with different buffers (final concentration of $50 \mathrm{mM}$ ) at $30^{\circ} \mathrm{C}$ for 7 days. Acetate buffer was used for $\mathrm{pH} 4.0$ 5.5, while phosphate buffer was used for $\mathrm{pH}$ 6.0-8.0 and Tris buffer for $\mathrm{pH} 8.5-10$. Similarly, the optimum salinity of the medium $(1-6 \%[\mathrm{w} / \mathrm{v}]$ at intervals of $0.5 \%$ unit $\mathrm{NaCl})$ was evaluated after 7 days of incubation at $30{ }^{\circ} \mathrm{C}$ in R2A medium. Tests were performed in the commercial systems API ZYM, API 20NE, and API ID 32GN (bioMerieux) as well, according to the manufacturer's instructions. The isoprenoid quinone test was performed as described by Hiraishi et al. ${ }^{37}$ For the analysis of cellular fatty acids, the $\mathrm{BS}^{2} 0^{\mathrm{T}}$ and two reference strains were harvested after $48 \mathrm{~h}$ of growth on R2A agar medium ( $\mathrm{pH} 7.0)$ at $30{ }^{\circ} \mathrm{C}$. The cellular fatty acids were saponified, methylated, and extracted according to the protocol of the Sherlock Microbial Identification System (MIDI). The fatty acid methyl esters were then analyzed using gas chromatography (model 6890; Hewlett Packard) with the microbial identification software package of the Sherlock system MIDI 6.1 and the Sherlock aerobic bacterial database (TSBA 6.1). ${ }^{38}$ The polar lipid content was extracted from $100 \mathrm{mg}$ of freeze-dried cells, examined by two-dimensional TLC, and then characterized as described previously. ${ }^{39}$

\subsection{Complete genome sequencing}

2.4.1. Genome sequencing and annotation. Due to its ability of ginsenoside-biotransformation, the $\mathrm{BS}^{2} 0^{\mathrm{T}}$ strain was chosen for whole genome sequence analysis. The genomic DNA was extracted and purified using the Genomic-tip system 100/G (QIAGEN, Japan). The genomic DNA was sequenced using the Pacific Biosciences RS II platform, and a library was constructed according to the instructions in the Pacific Biosciences RS II
Sequencing method manual. The sequence reads were assembled using the PacBio SMRT Analysis (version 2.3.0) with default options. The protein-coding sequences (CDS) were predicted using Glimmer 3.02, ${ }^{40}$ and the genome annotation was performed using the NCBI Prokaryotic Genome Automatic Annotation Pipeline (PGAP, http://www.ncbi.nlm.nih.gov/books/ NBK174280/). The rRNAs and tRNAs were predicted using rRNAmmer and tRNAscan-SE, respectively. Genome annotation and analysis were performed using the RAST server. ${ }^{41}$ Additional gene prediction analysis and functional annotation were performed with the Integrated Microbial Genomes-Expert Review (IMG-ER) platform..$^{42}$ The project information is available from the Genomes OnLine Database ${ }^{43}$ and the complete genome sequence has been submitted in GenBank.

2.4.2. Nucleotide sequence accession number. The complete genome sequence of the novel strain has been deposited at DDBJ/EMBL/GenBank under the accession number CP015971. This strain is available from the Korean Agricultural Culture Collection, South Korea with the accession number KACC $18624^{\mathrm{T}}$ and Belgian Coordinated Collections of Microorganism (BCCM/LMG) with the accession number LMG $29195^{\mathrm{T}}$ as well as from the host institution (Hankyong National University, Anseong-si, South Korea).

\subsection{Phylogenetic analysis of BglAg-762}

Database homology search was performed with BLAST program provided by NCBI. Sequences of the characterized glycosyl hydrolases were obtained from the CAZY database [Carbohydrate-Active enZymes database (http://www.cazy.org)], and multiple alignments were performed using the CLUSTAL_X program. $^{28}$ Gaps were edited in the BioEdit program, ${ }^{29}$ and evolutionary distances were calculated using a Poisson model. A phylogenetic tree was constructed using the neighbor-joining algorithm $^{31}$ in the MEGA6 program, ${ }^{33}$ with bootstrap values based on 1000 replicates. $^{35}$

\subsection{Molecular cloning, expression, and purification of the novel recombinant BglAg-762 enzyme}

A $\beta$-glucosidase belonging to the glycoside hydrolase family 3 can hydrolyze the glucose molecules attached to the $\mathrm{C} 3, \mathrm{C} 6$, or C20 position of the major ginsenosides. The gene encoding $\beta$-glucosidase was identified by analyzing the complete genome sequence, and the oligonucleotide primers used for cloning were designed based on the DNA sequence of BglAg-762 (GenBank accession no. CP015971). These primers were designed as forward (5'-GGTTCCGCGTGGATCCAAAAAAT CAATCGTAAAAATTT-3') and reverse (5'-GATGCGGCCGCTC GAGTTATTTGCTCCAATCAATAGCT-3') by Macrogen Co. Ltd. Korea were used to introduce the BamHI and XhoI restriction sites, respectively. After amplification with PCR, the amplified DNA fragments were purified and inserted into the pGEX4T-1 GST fusion vector using an EzCloning Kit (Enzynomics Co. Ltd., Korea). The resultant recombinant pGEX-BglAg-762 was used to transform E. coli BL21 (DE3). The recombinant E. coli BL21 (DE3) containing a plasmid with the target gene (BglAg762) was grown in an LB-ampicillin medium at $37{ }^{\circ} \mathrm{C}$ until 
the culture achieved an $\mathrm{OD}_{600}$ value of $0.4-0.6$. At this point, the protein expression was induced by adding $0.1 \mathrm{mM}$ isopropyl- $\beta$ D-thiogalactopyranoside (IPTG), and the cells were incubated for 24 hours at $28{ }^{\circ} \mathrm{C}$. After this incubation, the cells were harvested through centrifugation and were then washed twice with $1 \%$ Triton solution (100 mM sodium phosphate and $1 \%$ Triton $\mathrm{X}$ 100 at $\mathrm{pH} 7.0)$ and the pallets $(1 \mathrm{~g} / 10 \mathrm{~mL})$ were resuspended in $100 \mathrm{mM}$ sodium phosphate $(\mathrm{pH}$ 7.0). Cell sonication was carried out using the Branson Digital Sonifier ( $400 \mathrm{~W}, 70 \%$ power, USA) using the following settings: low power (36\%) output, $5 \mathrm{~s} \mathrm{ON} / 5 \mathrm{~s}$ OFF pulses, $\pm 5{ }^{\circ} \mathrm{C}$ water bath but no floating ice. The total sonication time was $10 \mathrm{~min}$. The crude cell extract was retained and the unwanted cell debris was removed by centrifugation (5000 rpm, for $10 \mathrm{~min}$ at $4{ }^{\circ} \mathrm{C}$ ). The GST tag was purified using the GST-bind agarose resin (Elpisbiotech Co. Ltd, Korea) and the homogeneity of the protein was assessed using 10\% SDS-PAGE and an EZStain Aqua solution (ATTO Corporation, Japan). The SDS PAGE analysis showed a difference between the molecular weights of the well-localized proteins in the gel (around $90 \mathrm{kDa}$ ) and the full-length sequence $(102 \mathrm{kDa})$. After the purification of BglAg-762, the molecular weight of the recombinant enzyme was confirmed to be around $90 \mathrm{kDa} \cdot{ }^{44-46}$

2.6.1. Effect of $\mathbf{p H}$, temperature, and metal ions on enzyme activity. The specific activity of BglAg-762 was determined by incubating the samples in $100 \mathrm{mM}$ sodium phosphate buffer ( $\mathrm{pH}$ 7.0), with $p$-nitrophenyl- $\beta$-D-glucopyranoside ( $p \mathrm{NPG}$ ) as a surrogate substrate, for $10 \mathrm{~min}$ at $37^{\circ} \mathrm{C}$. After $10 \mathrm{~min}$, the reaction was stopped by adding $0.5 \mathrm{M}$ (final concentration) $\mathrm{Na}_{2} \mathrm{CO}_{3}$, and the amount of $p$-nitrophenol released was quickly measured using a microplate reader at $405 \mathrm{~nm}$ (Bio-Rad model 680; Bio-Rad, Hercules, CA). One unit of enzyme activity was defined as the amount of enzyme required to produce $1 \mu \mathrm{mol}$ of $p$-nitrophenol in $1 \mathrm{~min}$. The specific activity of the enzyme was expressed as units per milligram of enzyme. The protein concentration was determined using the Bio-Rad protein assay (catalog number 500-0006) with bovine serum albumin (Sigma) as the standard. All assays were performed in triplicate.

Most enzymes are very sensitive to their surrounding $\mathrm{pH}$ and temperature, and very high or low $\mathrm{pH}$ values generally result in complete loss of activity. Therefore, the effect of $\mathrm{pH}$ on the activity of BglAg-762 was determined using 1.0 mM $p$ NPG as a substrate in the following buffers, each at $50 \mathrm{mM}$ : $\mathrm{KCl}-\mathrm{HCl}$ $(\mathrm{pH} 2.0)$, glycine- $\mathrm{HCl}$ or citrate $(\mathrm{pH} 3.0)$, sodium acetate $(\mathrm{pH}$ 4.0 and 5.0), sodium phosphate ( $\mathrm{pH} \mathrm{6.0,7.0,} \mathrm{and} \mathrm{7.5),} \mathrm{Tris-} \mathrm{HCl}$ (pH 8.0, and 9.0), and glycine-sodium hydroxide or carbonate (pH 10). $\mathrm{pH}$ stability was measured by incubating the mixture of the sample and the buffer (containing BglAg-762 enzyme and $2.0 \mathrm{mM} p \mathrm{NPG}$ in $50 \mathrm{mM}$ potassium buffer) for $12 \mathrm{~h}$ at $4{ }^{\circ} \mathrm{C}$. After $12 \mathrm{~h}$, the percentage of activity gained at the optimum $\mathrm{pH}$ was measured. To investigate the effect of temperature on the activity of BglAg-762, and to determine the optimum temperature for its activity, the samples were incubated at the optimum $\mathrm{pH}$ for $5 \mathrm{~min}$ in $50 \mathrm{mM}$ potassium phosphate buffer with $2.0 \mathrm{mM} p$ NPG under various temperatures $(4,10,20,25$, $30,37,40,45,50,55$, and $\left.60^{\circ} \mathrm{C}\right)$. As BglAg-762 was very sensitive to temperature, the thermo-stability of the enzyme was observed by incubating the samples in $50 \mathrm{mM}$ potassium phosphate buffer for different periods of time $(5 \mathrm{~min}, 10 \mathrm{~min}$, $30 \mathrm{~min}, 1 \mathrm{~h}, 2 \mathrm{~h}, 4 \mathrm{~h}$, and $16 \mathrm{~h}$ ) at the different temperatures (4$60{ }^{\circ} \mathrm{C}$ ). After the preset time intervals, the samples were collected and the enzymatic activity was determined using $p$ NPG as the substrate.

Metals and heavy metals are naturally occurring elements with high atomic weight and density. Therefore, the enzyme activity is affected by heavy metal availability and concentration as well. High concentrations of heavy metals are toxic to the active site of protein and could inhibit enzyme activity. Thus, the effects of metals and other chemicals on BglAg-762 activity were also determined. BglAg-762 activity was assessed in the presence of 1 and $10 \mathrm{mM}$ (final concentration) of $\mathrm{NaCl}, \mathrm{KCl}$, $\mathrm{CaCl}_{2}, \mathrm{MgCl}_{2}, \mathrm{CoCl}_{2}, \mathrm{MnSO}_{4}, \mathrm{MgSO}_{4}, \beta$-mercaptoethanol, and EDTA for $10 \mathrm{~min}$ at $50{ }^{\circ} \mathrm{C}$. The retained activity was determined using $p$ NPG as a substrate and expressed as a percentage of the activity in the absence of the compound.

It is commonly known that enzymes show different levels of activity for different substrates. Therefore, in this study, substrate preference of BglAg-762 was determined using $2.0 \mathrm{mM}$ chromogenic $o$-nitrophenyl $(o \mathrm{NP})$ and $p$-nitrophenyl $(p \mathrm{NP})$ as substrates. The samples were incubated at $37^{\circ} \mathrm{C}$ for $5 \mathrm{~min}$, and the enzyme activity was observed. One unit of enzyme activity (U) was defined as the amount of enzyme required to release $1 \mu \mathrm{mol}$ of $o \mathrm{NP}$ or $p \mathrm{NP}$ in $1 \mathrm{~min}$. The following substrates were tested: $p \mathrm{NP}-\beta-\mathrm{D}^{-}$ galactopyranoside, $p$ NP- $\beta$-D-glucopyranoside, $p$ NP- $\beta$-D-fucopyranoside, $p$ NP- $\beta$-L-arabinopyranoside, $p$ NP- $N$-acetyl- $\beta$-D-glucosaminide, $\quad p$ NP- $\beta$-D-mannopyranoside, $\quad p$ NP- $\beta$-D-xylopyranoside, $p$ NP- $\alpha$-D-glucopyranoside, $p \mathrm{NP}-\alpha$-L-arabinofuranoside, $p \mathrm{NP}-\alpha$-Larabinopyranoside, $p$ NP- $\alpha$-L-rhamnopyranoside, $p$ NP- $\alpha$-D-mannopyranoside, $p$ NP- $\alpha$-D-xylopyranoside, $o$ NP- $\beta$-D-glucopyranoside, $o \mathrm{NP}-\beta$-D-galactopyranoside, $o \mathrm{NP}-\beta$-D-fucopyranoside, and $o \mathrm{NP}-\alpha-$ D-galactopyranoside (all from Sigma).

2.6.2. Enzymatic transformation of major ginsenosides by BglAg-762. Initially, we tested the effect of the fused GST on the enzyme activity of BglAg-762. The biotransformation of ginsenosides, $\mathrm{Rb}_{1}, \mathrm{Rg}_{3}$, and $\mathrm{Re}$, showed that the fused GST did not affect the activity of BglAg-762. Therefore, the GST-fused enzyme (GST-BglAg-762) was used to determine the specificity and selectivity of BglAg-762 for the hydrolysis of glucose moieties attached to the $\mathrm{C} 3$ and $\mathrm{C} 20$ positions in six PPD-type $\left(\mathrm{Rb}_{1}, \mathrm{Rb}_{2}, \mathrm{Rb}_{3}, \mathrm{Rc}, \mathrm{Rd}\right.$, and Gyp-XVII) and two PPT-type (Re and $\mathrm{Rg}_{1}$ ) ginsenosides. The enzyme solution at a concentration of $0.4 \mathrm{mg} \mathrm{mL}^{-1}$ in $100 \mathrm{mM}$ of sodium phosphate buffer ( $\mathrm{pH} 7.0$ ) was mixed with equal volume of major ginsenosides $\mathrm{Rb}_{1}, \mathrm{Rb}_{2}$, $\mathrm{Rb}_{3}, \mathrm{Rc}, \mathrm{Rd}, \mathrm{Re}, \mathrm{Rg}_{1}$, and Gyp-XVII at a concentration of $1000 \mathrm{ppm}$ at $37^{\circ} \mathrm{C}$. At regular intervals of time, the samples were collected and analyzed by TLC or HPLC to assess the enzymatic biotransformation of PPD-type and PPT-type ginsenosides.

2.6.3. TLC analysis. TLC analysis was performed with $\mathrm{CHCl}_{3}-\mathrm{CH}_{3} \mathrm{OH}-\mathrm{H}_{2} \mathrm{O}$ (65: $35: 10$, lower phase) as a solvent in 60 $\mathrm{F}_{254}$ silica gel plates (Merck, Germany). The spots on the TLC plates were visualized by spraying $10 \%(\mathrm{v} / \mathrm{v}) \mathrm{H}_{2} \mathrm{SO}_{4}$ and heating at $110{ }^{\circ} \mathrm{C}$ for $5-10 \mathrm{~min}$, and then compared with ginsenoside standards. 


\section{Results and discussion}

3.1. Characterization of Arachidicoccus ginsenosidimutans sp. nov.

Arachidicoccus ginsenosidimutans (gin.se.no.si.di.mu'tans. N.L.n. ginsenosidum ginsenoside; L. part. adj. mutans transforming, converting; N.L. part. adj. ginsenosidimutans ginsenosideconverting).

After screening 15 novel bacterial species isolated from various sources, including ginseng soil and compost, the ability of these isolates to convert ginsenosides was tentatively determined by TLC analysis (data not shown). One of 15 novel species, designated as $\mathrm{BS}^{2} 0^{\mathrm{T}}$, was characterized using a polyphasic approach to clarify its taxonomic position. After complete genomic analysis of this strain, a novel ginsenoside-hydrolyzing $\beta$-glucosidase was identified and characterized.
Cells of the $\mathrm{BS}^{2} 0^{\mathrm{T}}$ strain were Gram-negative, aerobic, nonmotile, and short rod-shaped, approximately $0.5-2.0 \mu \mathrm{m}$ in length and $0.4-0.6 \mu \mathrm{m}$ in diameter (Fig. S2 $\dagger$ ). After $48 \mathrm{~h}$ of incubation on R2A agar medium, the colonies were 2-4 $\mathrm{mm}$ in diameter, flat, circular, smooth, entire, and had a milky color. Optimum growth occurred at $30{ }^{\circ} \mathrm{C}\left(15-37{ }^{\circ} \mathrm{C}\right)$ and the optimum pH was 6-7 (pH 6.0-9.0). The $\mathrm{BS}_{20}{ }^{\mathrm{T}}$ strain grew well on the R2A medium, weakly on nutrient agar, Luria Bertani, and DNase agar, and did not grow at all on trypticase soy agar and MacConkey agar. Growth occurred at $\mathrm{NaCl}$ concentrations ranging from 0 to $1 \%$. $\mathrm{BS} 20^{\mathrm{T}}$ cells were positive for catalase, oxidase, and esculin hydrolysis activities, but negative for hydrolysis of cellulose, Tween-80, starch, Tween-20, chitin, tyrosine and casein. When tested in API (20NE, $32 \mathrm{GN}$, and API ZYM) systems, the cells were positive for alkaline phosphatase, esterase, leucine arylamidase, valine arylamidase, cystine arylamidase, acid phosphatase,

Table 1 Differentiating characteristics of strain $\mathrm{BS}_{20}^{\top}$ and the type strains of related Arachidicoccus species. Strain: (1) strain BS20 ${ }^{\top}$; (2) $A$. ginsenosidivorans KCTC $22820^{\top}$; (3) A. rhizosphaerae KCTC $22378^{\top}$. The data presented here are from this study. In API kit system (ZYM, 20NE and $32 \mathrm{GN}$ ), all strains were positive for alkaline phosphatase, esterase, leucine arylamidase, valine arylamidase, cystine arylamidase, acid phosphatase, naphtol-AS-BI-phosphohydrolase, $\alpha$-galactosidase, $\beta$-galactosidase, $\alpha$-glucosidase, $\beta$-glucosidase, $N$-acetyl- $\beta$-glucosaminidase, $\alpha$-fucosidase, esculin, 4-nitrophenyl- $\beta$-D-galactopyranoside, L-rhamnose, $N$-acetyl-glucose, $D$-saccharose and $D$-maltose. While, negative for lipase, trypsin, indole production, urea, gelatin, itaconic acid, suberic acid, sodium malonate, sodium acetate, lactic acid, L-alanine, potassium 5 ketogluconate, 3-hydroxybenzoic acid, L-serine, L-fucose, D-sorbitol, propionic acid, capric acid, valeric acid, trisodium citrate, potassium 2-ketogluconate, 3-hydroxybutyric acid, 4-hydroxybenzoic acid, potassium gluconate, adipic acid, malic acid, trisodium citrate, inositol and phenylacetic acid. Besides the commercial API kit system, all strains were positive for conversion of PPD-mix type ginsenosides and for activities the catalase oxidase, respectively. (+) Positive; $(-)$ negative

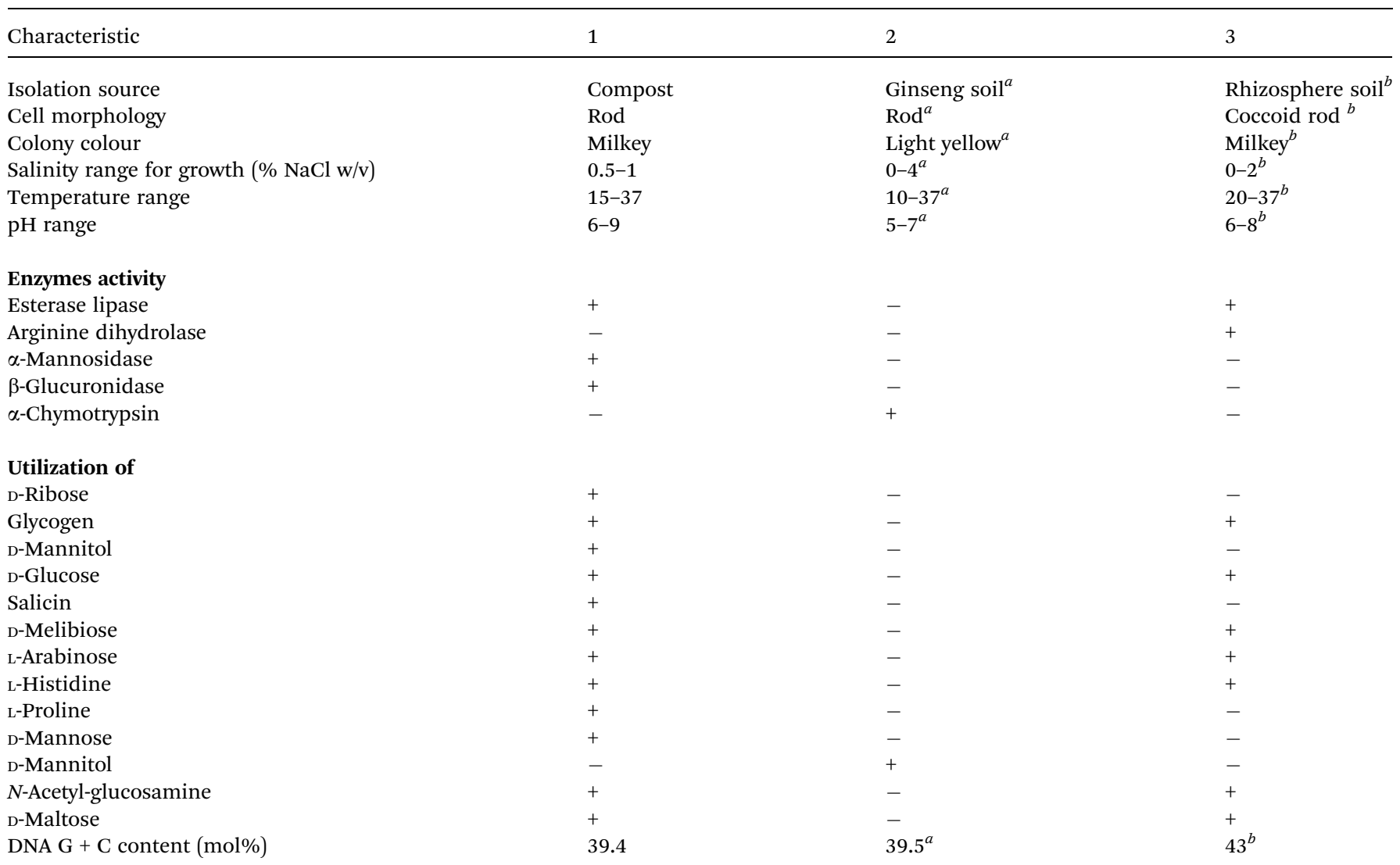

${ }^{a}$ Data taken from: A. ginsenosidivorans KCTC $22820^{\mathrm{T}}$ (Siddiqi et al. 2017). ${ }^{b}$ Data taken from: A. rhizosphaerae $\mathrm{KCTC}^{22378^{\mathrm{T}}}$ (Madhaiyan et al. 2015). 
naphtol-AS-BI-phosphohydrolase, $\alpha$-galactosidase, $\beta$-galactosidase, $\alpha$-glucosidase, $\beta$-glucosidase, $N$-acetyl- $\beta$-glucosaminidase, $\alpha$-fucosidase, L-rhamnose, $N$-acetyl-glucose, $\quad D^{-}$ saccharose, and D-maltose. The cells were negative for indole production, urea, gelatin, lipase, trypsin, potassium gluconate, capric acid, adipic acid, malic acid, phenylacetic acid, potassium 2-ketogluconate, 3-hydroxybutyric acid, 4-hydroxybenzoic acid, propionic acid, 3-hydroxybenzoic acid, valeric acid, trisodium citrate, L-fucose, D-sorbitol, L-serine, itaconic acid, suberic acid, sodium malonate, sodium acetate, lactic acid, L-alanine, potassium-5-ketogluconate, and inositol in these systems. The phenotypic differences between the $\mathrm{BS} 20^{\mathrm{T}}$ and other closely related species in the same genus, based on phylogenetic analysis, are summarized in Table 1 . The predominant fatty acids in these cells were iso- $\mathrm{C}_{15: 0}$, iso- $\mathrm{C}_{15: 1}$ $\mathrm{G}$, iso- $\mathrm{C}_{17: 0} 3-\mathrm{OH}$, and summed feature 3 (comprising $\mathrm{C}_{16: 1}$ $\omega 7 \mathrm{c}$ and/or $\mathrm{C}_{16: 1} \omega 6 \mathrm{c}$ ). The cellular fatty acid profiles of $\mathrm{BS}_{20} \mathrm{~T}^{\mathrm{T}}$ and two reference strains grown under identical conditions are summarized in Table 2. These results suggested that this newly isolated bacterium belonged to the genus Arachidicoccus. The major polar lipids in these cells were PE and an unknown polar lipid (L2), while six unidentified minor polar lipids (L1, L3, L4, L5, L6, and L7), two unknown aminophospholipids (APLl and APL2), and two unknown phospholipids (PL1 and PL2) were found (Fig. S3†). The only predominant menaquinone in this strain was MK-7. The G + C

Table 2 Cellular fatty acid profiles of strain $\mathrm{BS}^{2} \mathrm{O}^{\top}$ and phylogenetically related species of the genus Arachidicoccus. Strain: (1) strain $\mathrm{BS}^{2} \mathrm{O}^{\top}$; (2) A. ginsenosidivorans KCTC $22820^{\top}$; (3) A. rhizosphaerae KCTC $22378^{\top}$. All strains were cultured on R2A agar for $48 \mathrm{~h}$ at $30^{\circ} \mathrm{C}$. Fatty acids amounting to $<0.5 \%$ of the total fatty acids in all strains are not listed. (-) Not detected

\begin{tabular}{llll}
\hline Fatty acids & 1 & 2 & 3 \\
\hline
\end{tabular}

\begin{tabular}{llll}
\hline Saturated & & & \\
$\mathrm{C}_{14: 0}$ & 0.5 & 0.3 & 0.8 \\
$\mathrm{C}_{16: 0}$ & 6.0 & 3.8 & 6.8 \\
$\mathrm{C}_{18: 0}$ & - & 0.3 & 1.7 \\
$\mathrm{C}_{20: 0}$ & - & - & 0.8
\end{tabular}

\section{Branched}

Iso- $\mathrm{C}_{15: 0}$

Iso- $\mathrm{C}_{15: 0} 3-\mathrm{OH}$

Iso- $_{15: 1} \mathrm{G}$

Anteiso- $\mathrm{C}_{15: 0}$

Iso- $_{16: 0} 3-\mathrm{OH}$

Iso- $_{17: 0} 3-\mathrm{OH}$

Hydroxy

$\mathrm{C}_{16: 0}$ 2-OH

$\mathrm{C}_{16: 0} 3-\mathrm{OH}$

$\mathrm{C}_{17: 0} 2-\mathrm{OH}$

Summed feature ${ }^{a}$

$3 ; \mathrm{C}_{16: 1} \omega 7 \mathrm{c}$ and/or $\mathrm{C}_{16: 1} \omega 6 \mathrm{c}$

10.8

9.3

42.7

2.7

14.9

0.9

$0.8 \quad 0.9$

$17.0 \quad 20.7$

$6.2 \quad 0.3$

$5.4 \quad 3.8$

$0.5-$

${ }^{a}$ Summed features represent groups of two or three fatty acids that could not be separated by gas chromatography (GLC) with the MIDI system. Summed features consist of: $3, \mathrm{C}_{16: 1} \omega 7 \mathrm{c}$ and/or $\mathrm{C}_{16: 1} \omega 6 \mathrm{c}$. content in the DNA was 39.4 mol\%. Tables 1 and 2 show the characteristics used to distinguish $\mathrm{BS}^{2} 0^{\mathrm{T}}$ from the other related species in the genus Arachidicoccus.

The nearly complete $16 \mathrm{~S}$ rRNA gene sequence (1450 nt) of the $\mathrm{BS}_{20} \mathrm{O}^{\mathrm{T}}$ strain was determined and subjected to comparative analysis. Phylogenetic analysis using the maximum likelihood method based on 16S rRNA gene sequences indicated that $\mathrm{BS} 20^{\mathrm{T}}$ was clustered within the genus Arachidicoccus and occupied an intra-genus clade with $A$. ginsenosidivorans KCTC $14980^{\mathrm{T}}$ and A. rhizosphaerae KCTC $22378^{\mathrm{T}}$ (Fig. 1). This relationship was also evident from the phylogenetic trees constructed with the neighbor-joining and maximum-parsimony methods. Further, the $16 \mathrm{~S}$ rRNA gene of the strain $\mathrm{BS}_{20}{ }^{\mathrm{T}}$ exhibited the highest sequence similarity to $A$. ginsenosidivorans $\mathrm{KCTC} 22820^{\mathrm{T}}(95.0 \%)$ and A. rhizosphaerae KCTC $22378^{\mathrm{T}}(94.0 \%)$.

Based on the 16S rRNA gene sequence and the phylogenetic analysis, A. ginsenosidivorans KCTC $22820^{\mathrm{T}}$ and A. rhizosphaerae KCTC $22378^{\mathrm{T}}$ were selected as the closest recognized neighbors of the $\mathrm{BS}^{2} 0^{\mathrm{T}}$ strain. These strains were then obtained from culture collections, grown under the same conditions, and used as reference strains in the subsequent phenotypic tests.

On the basis of low 16S rRNA-sequence similarity (<95\%), phylogenetic position, and phenotypic and chemotaxonomic characteristics, a new taxon in the family Chitinophagaceae of phylum Bacteroidetes, named Arachidicoccus ginsenosidimutans sp. nov., was proposed, and the type strain for this species was proposed to be strain $\mathrm{BS}^{\mathrm{T}} \mathrm{T}^{\mathrm{T}}\left(=\right.$ KACC $18624^{\mathrm{T}}=$ LMG $29195^{\mathrm{T}}$ ). Phylogenetically, the novel isolate was related to the genus Arachidicoccus and shared several common features with members of this genus (MK-7 as the major respiratory quinone, $\mathrm{PE}$ as the major polar lipid, branched fatty acids with odd number of carbons, and the presence of a distinctive methoxy-fatty acid [iso- $\left.\mathrm{C}_{17: 0} 3-\mathrm{OH}\right]$ ). The GenBank accession number for the 16S rRNA gene sequence of this strain is JF806524.

\subsection{Genome properties of strain $\mathrm{BS}^{\mathrm{T}} \mathrm{T}^{\mathrm{T}}$}

The $\mathrm{BS}_{20}^{\mathrm{T}}$ strain had a circular chromosome with $4138017 \mathrm{bp}$ and a $\mathrm{G}+\mathrm{C}$ content of $39.4 \mathrm{~mol} \%$. The genome sequence has been deposited in GenBank nucleotide database under the accession number CP015971. The genome statistics are shown in Table 3 and Fig. 2. Of the 3043 genes predicted, 2998 were protein-coding genes, and 45 were RNAs; 27 pseudogenes were also identified. The majority of the protein-coding genes (98.2\%) were assigned a putative function, while the remaining was annotated as hypothetical or conserved hypothetical proteins (Table 3).

\subsection{Phylogenetic analysis of sequence of BglAg-762}

The $\beta$-glycosidase gene ( $\mathrm{BglAg}$ ) consists of 2286 bp encoding 762 amino acids with a molecular mass of $102.0 \mathrm{kDa}$ and a theoretical pI value of 6.15 (http://web.expasy.org/compute_pi/). Amino acid sequence analysis of the of BglAg-762 indicated that it has bellow than $69.0 \%$ similarity to the glycoside hydrolase of Niabella ginsenosidivorans (GenBank number WP 067760954) 


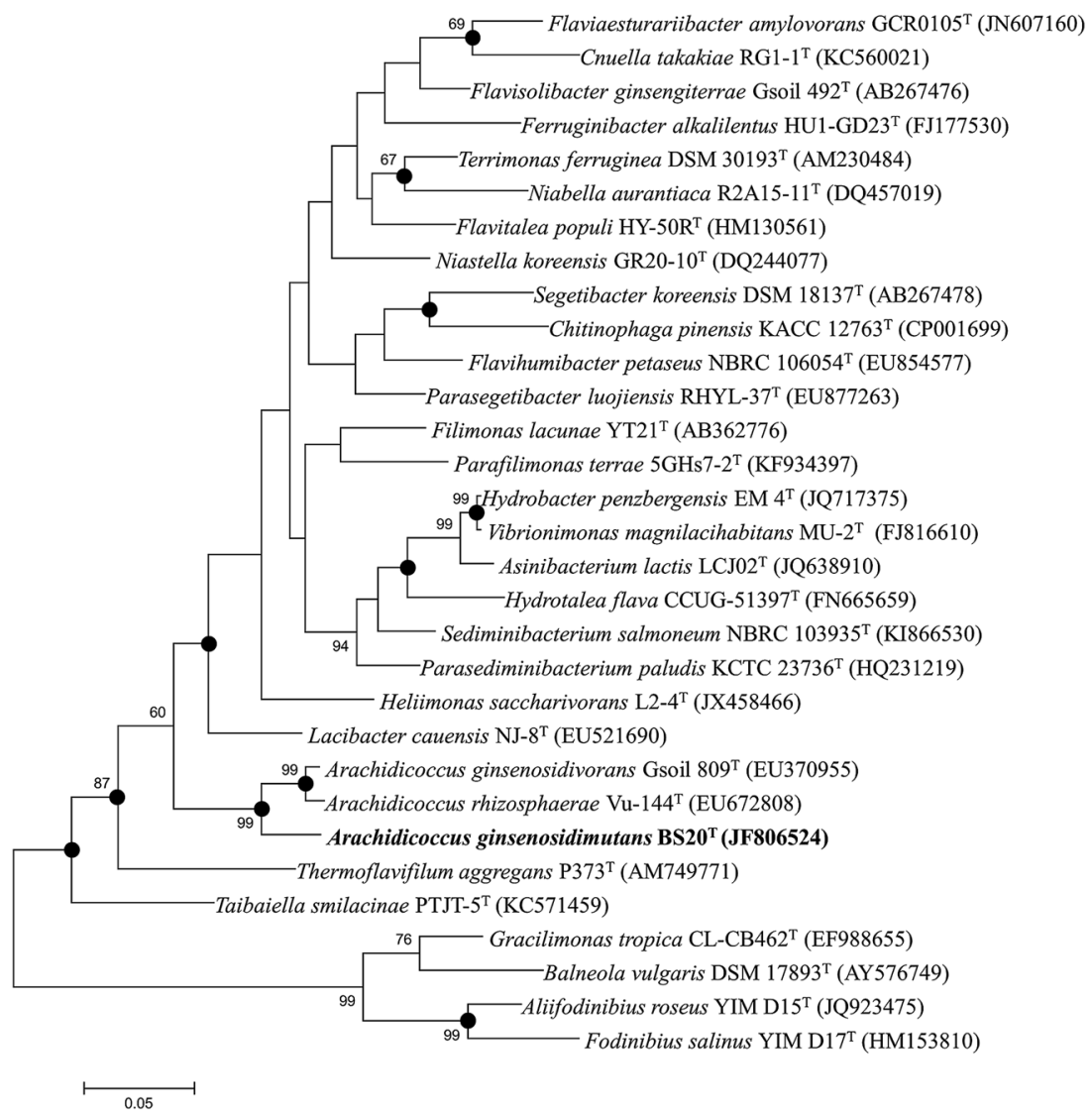

Fig. 1 Phylogenetic relationship of strain $\mathrm{BS}^{2} \mathrm{O}^{\top}$, recognized as Arachidicoccus species, and other related genera in the family Chitinophagaceae. The tree was constructed using the maximum-likelihood method based on 16S rRNA gene sequences. Bootstrap values (expressed as percentages of 1000 replications) greater than $60 \%$ are shown at branch points. Filled circles indicate that the corresponding nodes were also recovered in the tree generated with maximum-parsimony and neighbor-joining algorithms. Bar represents 0.05 substitutions per nucleotide position.

Table 3 Genome features of strain BS20 ${ }^{\top}$

\begin{tabular}{ll}
\hline Features & Chromosome \\
\hline Length (bp) & 4138017 \\
DNA coding region (bp) & 3724510 \\
G + C content (\%) & 39.4 \\
Genes & 3043 \\
Pseudo genes & 27 \\
CDS & 2998 \\
rRNA gene & 6 \\
tRNA genes & 39
\end{tabular}

and other uncharacterized glycoside hydrolases, which belong to glycoside hydrolase family 3 (GH3). This means that BglAg762 has homology to the protein domain of GH3. The Carbohydrate-Active enZymes database (http://www.cazy.org) describes more than 5000 uncharacterized and 222 characterized GH3 members that are widespread across numerous organisms. The glycoside hydrolase family 3 (GH3) is subdivided into six subfamilies. ${ }^{48}$ In order to determine the evolutionary position of BglAg-762 within the characterized enzymes in glycoside hydrolases family 3 , a phylogenetic analysis was conducted using the neighbor-joining method in the MEGA6 program with bootstrap values based on 1000 replications (Fig. 3). The phylogenetic tree analysis indicate that BglAg-762 clustered within subfamily 6 and formed a separate and wellsupported group (bootstrap of 100) with $\beta$-glucosidase derived from Escherichia coli [(AAA60495) uncharacterized] and Chrysosporium lucknowense, ${ }^{47}$ which was characterized.

\subsection{Molecular cloning of $\beta$-glucosidase gene (BglAg-762) from strain BS20 ${ }^{\mathrm{T}}$}

Genomic DNA from strain $\mathrm{BS} 20^{\mathrm{T}}$ was isolated and subjected to complete genome sequencing by Macrogen, Korea. From this analysis, 17 sets of 4 different glycoside hydrolase genes, including $\beta$-glucosidase ( 8 sets), $\alpha, \beta$-xylosidase ( 4 sets), $\mathrm{L}^{-}$ rhamnosidase ( 2 sets), and $\alpha, \beta$-arabinofuranosidase ( 3 sets) were selected and used for gene cloning. The sequences of the oligonucleotide primers used for the gene cloning were based on the DNA sequences of $\beta$-glucosidase, $\alpha, \beta$-xylosides, L-rhamnosidase, and $\alpha, \beta$-arabinofuranosidase (Table S1 $\dagger$ ). These primers were designed with BamHI and XhoI restriction sites, respectively, and were synthesized by Macrogen Co. Ltd. (Korea). 

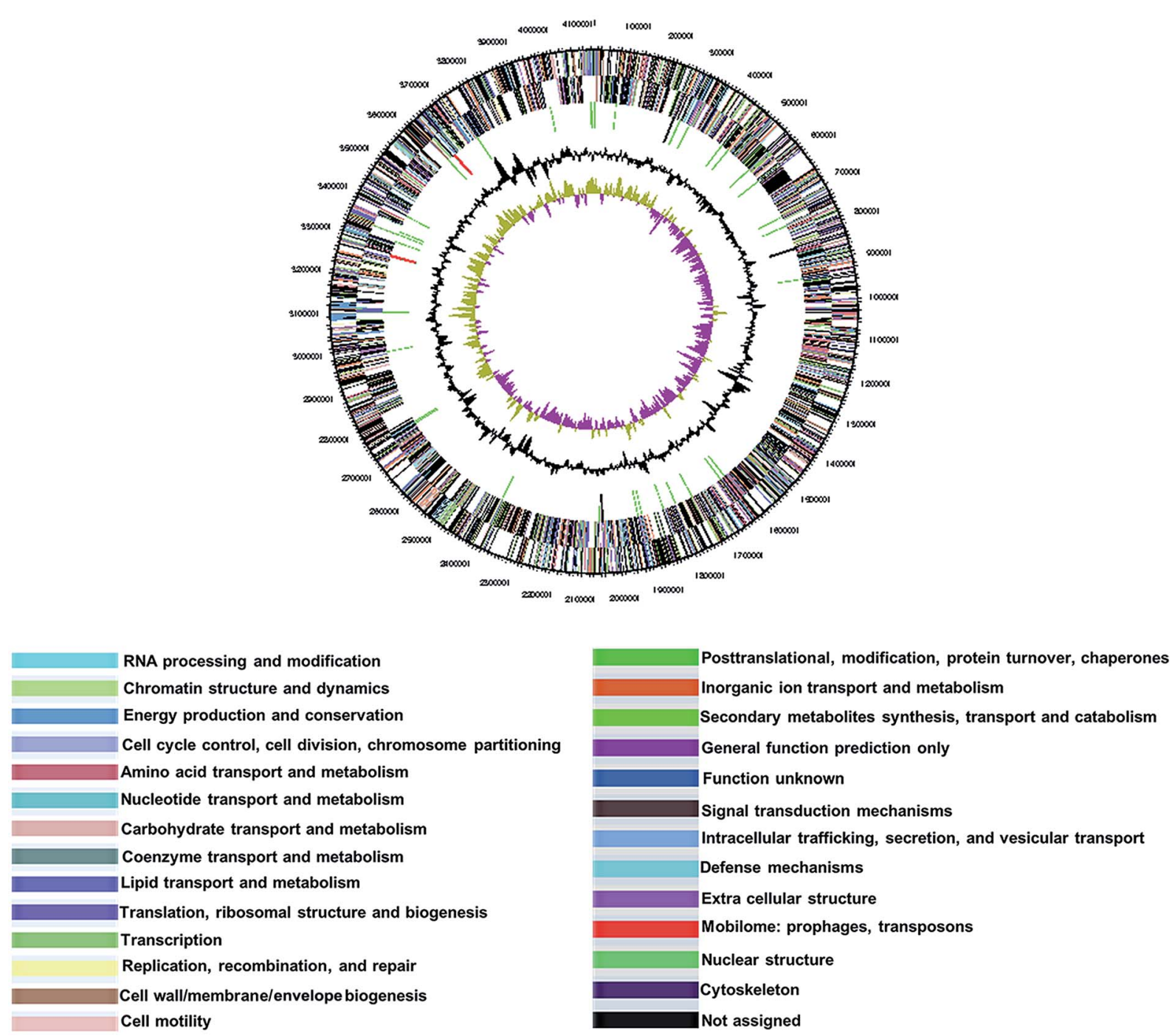

Fig. 2 Graphical map of the chromosome of strain $B S 2 O^{\top}$. From outside to the center: genes on the forward strand (colored by COG categories), genes on the reverse strand (colored by COG categories), RNA genes (tRNAs, green; rRNAs, red; other RNAs, black), and GC content and GC skew.

After cloning, some sets of clones from the $\mathrm{BS}_{2} 0^{\mathrm{T}}$ strain showed positive activities for $p$ NP- $\beta$-D-glucopyranoside, $p$ NP- $\beta$-D-galactopyranoside, $p$ NP- $\beta$-D-fucopyranoside, $p$ NP- $N$ acetyl- $\beta$-D-glucosaminide, $p$ NP- $\beta$-L-arabinopyranoside, $p$ NP- $\beta$ D-mannopyranoside, $p$ NP- $\beta$-D-xylopyranoside, $p$ NP- $\alpha$-D-glucopyranoside, $p \mathrm{NP}-\alpha$-L-arabinofuranoside, $p \mathrm{NP}-\alpha$-D-fucopyranoside, $p$ NP- $\alpha$-L-rhamnopyranoside, $p$ NP- $\alpha$-D-mannopyranoside, $o \mathrm{NP}-\beta$-D-glucopyranoside, $o \mathrm{NP}-\beta$-D-fucopyranoside, and $o \mathrm{NP}-\alpha-$ D-galactopyranoside (Table 4). Among the 17 sets of clones, only one (BglAg-762) was found to be positive for the ability to convert ginsenosides (Table 4), and was selected for use in further experiments. Based on amino acid-sequence analysis, BglAg-762 (GenBank accession number: CP015771) was predicted to have a molecular weight of $102 \mathrm{kDa}$. The amino acidsequence analysis also indicated that it was $69 \%$ identical to the glycoside hydrolase of Niabella ginsenosidivorans (GenBank accession number: CP015772), which also belongs to glycoside hydrolase family 3 . The enzymatic activity of the glycoside hydrolase from Niabella ginsenosidivorans has not yet been characterized. The glycoside hydrolase are classified according to amino acid-sequence similarity, as it has been shown to reflect the structural features of the enzymes, in addition to their substrate specificity (http://www.cazy.org/fam/ acc_GH.html). ${ }^{49}$ Kinetic studies were performed with freshly purified enzymes using $p$ NPG at 1-20 mM. Specific activity was expressed as units per milligram of protein. Protein concentrations were determined using the bicinchoninic acid (BCA) protein assay (Pierce, Rockford, IL), with bovine serum albumin (Sigma Aldrich, USA) as the standard. All assays were performed in triplicate.

\subsection{Recombinant protein expression and ginsenoside transformation by BglAg-762}

The recombinant pGEX-BglAg-762 was used to transform E. coli BL21 (DE3). The protein expression was then induced by the 


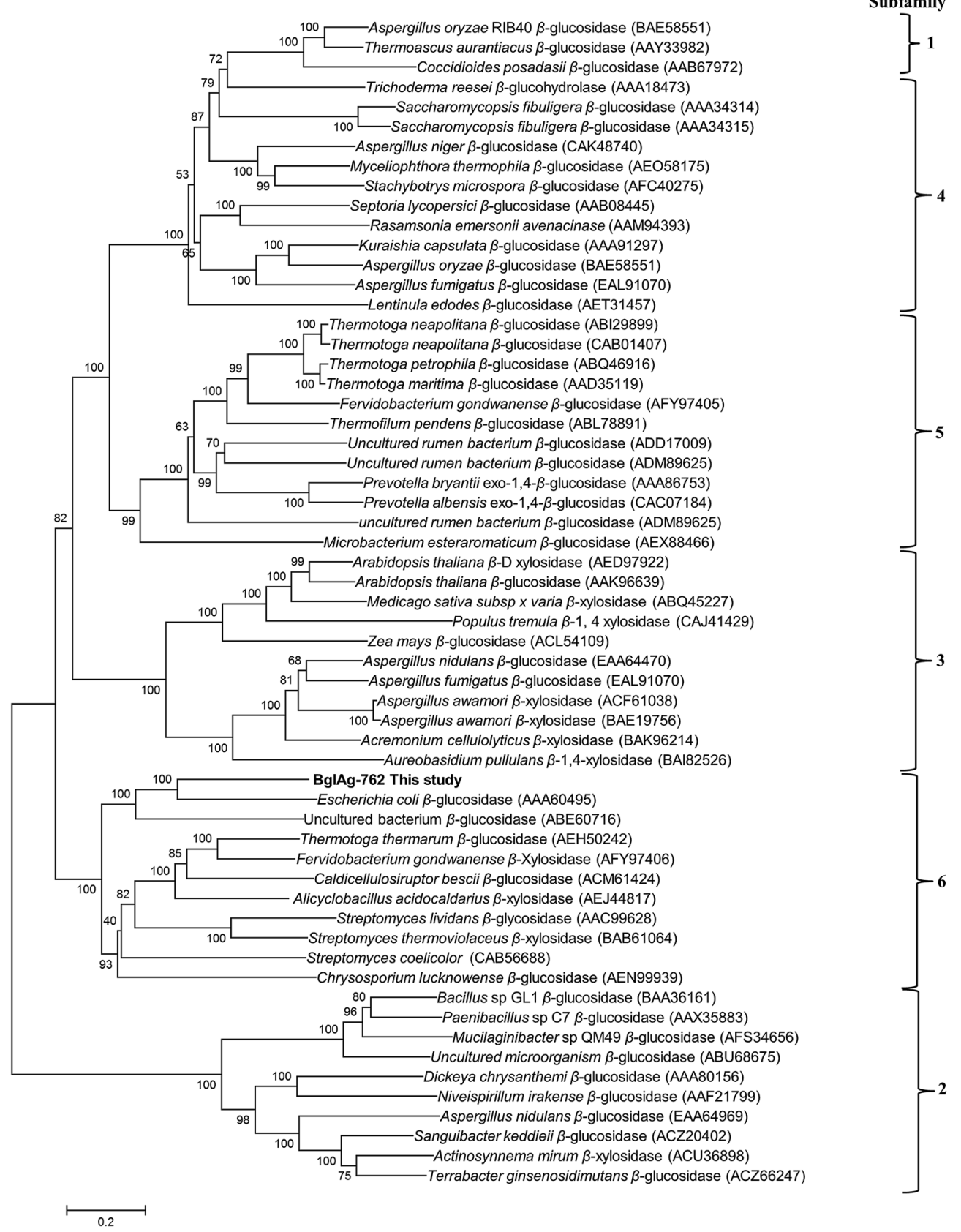

Fig. 3 Phylogenetic analysis of characterized and/or uncharacterized glycoside hydrolases family 3 (GH3). Amino acid sequences were obtained from NCBI/EMBL database and CAZy database (accession numbers are indicated on the tree). This tree was made using the neighbor-joining method with a Poisson model and pairwise deletion. Bootstrap values expressed as percentages of 1000 replications. The bar represents 20 amino acid residues substitutions per 100 amino acid residues.

addition of $0.1 \mathrm{mM}$ IPTG. In order to maximize the yield of the fusion protein, samples of the recombinant $E$. coli BL21 (DE3) grown in $\mathrm{LB}+\operatorname{amp}\left(1 \mathrm{~g} \mathrm{~mL}^{-1}\right)$ broth were kept in different temperatures $\left(18,22,25\right.$, and $\left.28{ }^{\circ} \mathrm{C}\right)$ with different induction conditions (0.05, 0.1, and $0.5 \mathrm{mM}$ IPTG [data not shown]). Incubation with $0.5 \mathrm{mM}$ IPTG at $28{ }^{\circ} \mathrm{C}$ for $18 \mathrm{~h}$ produced the maximum level of soluble active fused enzyme, as shown in Fig. 4 and S4. $\uparrow$ The ability of BglAg-762 to convert PPD-type $\left(\mathrm{Rb}_{1}\right.$, $\mathrm{Rb}_{2}, \mathrm{Rb}_{3}$, Rc, Rd, and GypXVII) and PPT-type ( $\mathrm{Re}$ and $\mathrm{Rg}_{1}$ ) major ginsenosides was assessed by performing TLC analysis of the enzyme hydrolysates at regular intervals. Based on the $R_{\mathrm{f}}$ values, it was clear that BglAg-762 could transform only PPD-type major ginsenosides, as it showed no activity in converting PPT-type ginsenosides, Re and $\mathrm{Rg}_{1}$ (Fig. 5). BglAg-762 could efficiently hydrolyze the glucose attached at the $\mathrm{C} 3$ and $\mathrm{C} 20$ positions of all six PPD-type ginsenosides. The proposed pathways for the biotransformation of $1 \mathrm{mg} \mathrm{mL} \mathrm{m}^{-1}$ of PPD-type ginsenosides by BglAg-762 are as follows: $\mathrm{Rb}_{1} \rightarrow$ Gyp-XVII $\rightarrow \mathrm{F}_{2} \rightarrow \mathrm{C}-\mathrm{k} ; \mathrm{Rb}_{2} \rightarrow$ $\mathrm{C}-\mathrm{O} ; \mathrm{Rb}_{3} \rightarrow \mathrm{C}-\mathrm{Mx}_{1}$; Rc $\rightarrow$ C-Mc $\mathrm{Mc}_{1} \rightarrow \mathrm{C}-\mathrm{Mc}$; Rd $\rightarrow \mathrm{F}_{2}$; and Gyp$\mathrm{XVII} \rightarrow \mathrm{F}_{2}$. The biotransformation occurs through the 
Table 4 Hydrolytic and ginsenoside conversion activities of 17 sets of clones of strain BS20. Clone sets. (1) $\beta$-Glucosidase-726; (2) $\beta$-glucosidase-762; (3) $\beta$-glucosidase-759; (4) $\beta$-glucosidase-957; (5) glucosidase-757; (6) $\beta$-glucosidase-747; (7) glucosidase-778; (8) glucosidase-796; (9) $\alpha$-xylosidase-1042; (10) xylosidase and/or arabinosidase-444; (11) $\alpha$-xylosidase-847; (12) $\beta$-xylosidase-519; (13) L-rhamnosidase-767; (14) Lrhamnosidase-881; (15) L-arabinofuranosidase-345; (16) L- $\beta$-arabinofuranosidase-688; (17) L- $\beta$-arabinofuranosidase-775. Enzyme activities of these 17 clones were expressed as relative activity \pm SD (\%) as shown; $(++)$ strong $(100.0 \pm 1.2)$ activity; $(+)$ moderate $(65.5 \pm 3.8)$ activity; $(w)$ week $(40.5 \pm 4.8 \%)$ activity; (vw) very weak (11.5 \pm 2.1$)$ activity; ( $)$ no activity

Enzyme activities of 17 different clones of Arachidicoccus ginsenosidivorans strain BS20

\begin{tabular}{|c|c|c|c|c|c|c|c|c|c|c|c|c|c|c|c|c|}
\hline Substrates $^{a}$ & 1 & $2^{c}$ & 3 & 4 & 5 & 6 & 7 & 8 & 9 & 10 & 11 & 12 & 13 & 14 & 15 & 16 \\
\hline$p$ NP- $\beta$-D-galactopyranoside & - & - & $\mathrm{w}$ & - & - & - & - & $\mathrm{w}$ & $\mathrm{w}$ & - & $\mathrm{w}$ & - & - & - & - & - \\
\hline$p$ NP- $\beta$-D-glucosaminide & - & - & $\mathrm{w}$ & - & - & $\mathrm{vw}$ & - & - & - & $\mathrm{vw}$ & vw & - & vw & - & - & $\mathrm{w}$ \\
\hline$p$ NP- $\beta$-L-arabinofuranoside & - & - & - & - & - & - & - & - & - & - & - & - & - & - & - & - \\
\hline$p$ NP- $\beta$-D-mannopyranoside & - & - & - & - & - & - & - & - & - & - & - & - & - & - & - & 一 \\
\hline$p$ NP- $\beta$-D-xylopyranoside & - & - & - & - & $\mathrm{vw}$ & - & - & - & - & - & - & - & - & - & - & - \\
\hline$p \mathrm{NP}-\alpha$-L-arabinofuranoside & - & - & - & - & - & - & - & - & $\mathrm{vw}$ & - & - & - & - & - & - & - \\
\hline$p$ NP- $\alpha$-D-fucopyranoside & - & - & - & - & - & - & - & - & - & $\mathrm{vw}$ & - & - & - & - & - & - \\
\hline$p N P-\alpha$-L-rhamnnopyranoside & - & - & - & - & - & - & - & - & - & - & - & - & - & - & - & - \\
\hline$p$ NP- $\alpha$-D-mannopyranoside & - & - & - & - & - & - & - & - & - & - & - & - & - & - & - & - \\
\hline$o$ NP- $\beta$-D-glucopyranoside & $\mathrm{w}$ & $\mathrm{w}$ & - & - & $\mathrm{w}$ & $\mathrm{vw}$ & - & - & vw & - & - & - & - & - & - & - \\
\hline$o$ NP- $\beta$-D-fucopyranoside & - & - & - & - & - & - & - & - & - & - & - & - & - & - & - & - \\
\hline
\end{tabular}

${ }^{a}$ Final concentration, $2.0 \mathrm{mM} .{ }^{b}$ Activity toward $p$ NP- $\beta$-D-glucopyranoside was set as $100 \% .{ }^{c}$ One unit of activity was defined as the amount of protein required to generate $1 \mu \mathrm{mol}$ of $p$-nitrophenol per min. Enzymes were purified ones.

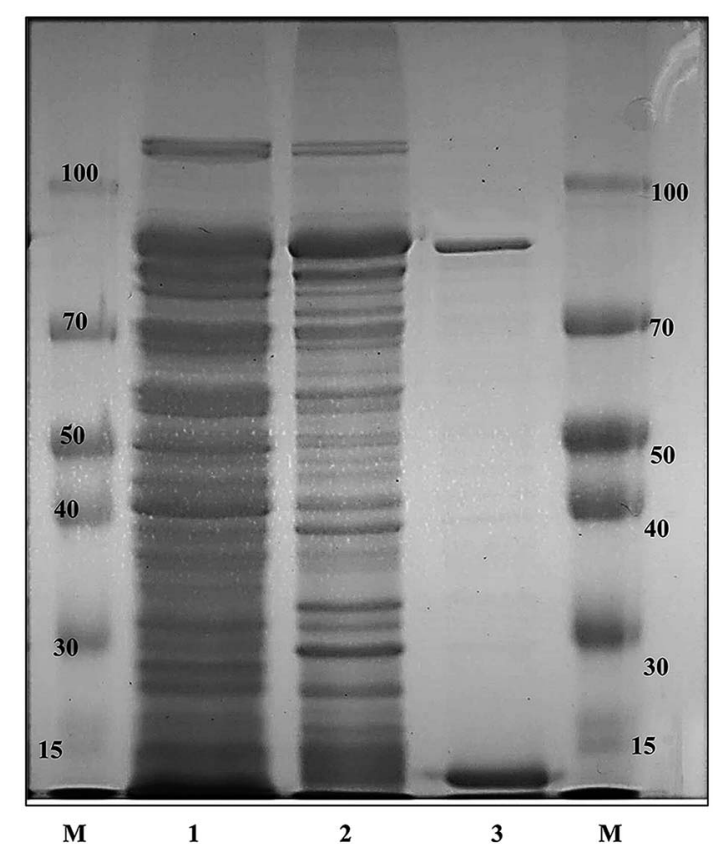

Fig. 4 SDS-PAGE analysis of recombinant BglAg-762. Lanes: (M) molecular weight standard; (1) crude extract of BL21 (DE3) carrying pGEX-BglAg-762 before induction; (2) soluble fraction of crude extract of BL21 (DE3) carrying pGEX-BglAg-762 after induction; (3) GST-BglAg-762 enzyme fraction after purification with the GST-bind agarose resin.

stepwise hydrolysis of the outer and inner glucose moieties at C3 and C20 positions of aglycon (Fig. 6). However, BglAg-762 could not further hydrolyze $\mathrm{C}-\mathrm{O}, \mathrm{C}-\mathrm{Mx}_{1}$, and $\mathrm{C}-\mathrm{Mc}_{1}$ even after incubating longer at $37{ }^{\circ} \mathrm{C}$. The ginsenoside $\mathrm{Rb}_{1}$ was initially transformed into Gyp-XVII and then converted into $\mathrm{F}_{2}$ within $10 \mathrm{~min}$ and finally convert into C-k after $4 \mathrm{~h}$ incubation at $37^{\circ} \mathrm{C}$. Further incubation of C-k together with recombinant enzyme (BglAg-762) show no more hydrolysis of C-k, indicating that the recombinant BglAg-762 preferred the outer glucose at the $\mathrm{C} 3$ or C20 position. Moreover, the rate of conversion was much faster than previously published crude enzyme extracts ( $\beta$-glucosidase) obtained from Caulobacter leidyia GP45 (ref. 50) and Bifidobacterium sp. $\mathrm{SH} 5,{ }^{51}$ which converted $1 \mathrm{mg} \mathrm{mL}^{-1}$ of $\mathrm{Rb}_{1}$ to Rd in 24 hours.

\subsection{Purification and characterization of recombinant BglAg- 762}

GST-bind agarose resin was used to purify the recombinant enzyme, GST-BglAg-762. The supernatant from cell lysate as well as the purified protein was subjected to $10 \%$ SDS-PAGE (Fig. 4 and S4 $\dagger$ ). From the SDS PAGE analysis, we found a difference between the molecular weights of the well-localized proteins in the gel (around $90 \mathrm{kDa}$ ) and the full-length sequence (102 kDa). After purifying BglAg-762, the molecular weight of the recombinant enzyme was confirmed to be around $90 \mathrm{kDa}$, as shown in Fig. 4 and S4. $\dagger$ The difference between the molecular weight of the recombinant protein BglAg-762 calculated from amino acid-sequence analysis and that calculated after protein purification might be due to self-proteolysis of the bacterial strain protein. ${ }^{44-46}$

The optimum $\mathrm{pH}$ and temperature for biotransformation were determined using crude BglAg-762. The BglAg-762 had optimal activity at pH 7.5 in a sodium phosphate buffer, and it 

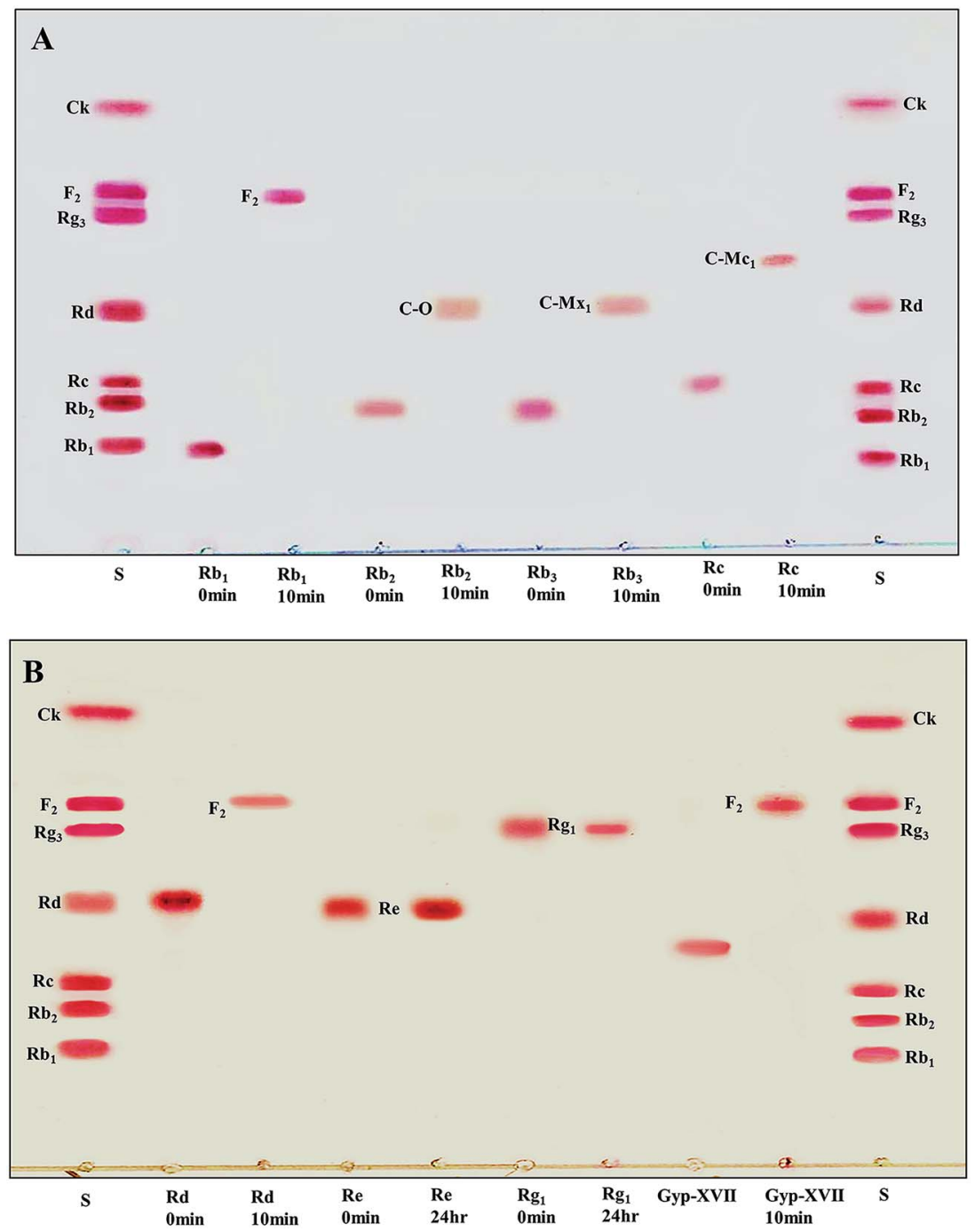

Fig. 5 (A and B) TLC analyses of time course of ginsenoside bioconversion by BglAg-762 at an enzyme concentration of $1 \mathrm{mg} \mathrm{mL}^{-1}$. (A) Enzymatic transformation of ginsenosides $\mathrm{Rb}_{1}, \mathrm{Rb}_{2}$, and Rc. (B) Enzymatic transformation of ginsenosides Rd and Gyp-XVII. PPT-type ginsenosides Re and $\mathrm{Rg}_{1}$ did not show any change. Developing solvent: $\mathrm{CHCl}_{3}-\mathrm{CH}_{3} \mathrm{OH}-\mathrm{H}_{2} \mathrm{O}(65: 35: 10$, v/v, lower phase). Lane $\mathrm{S}$, standards (Rb $\mathrm{Rb}_{2}, \mathrm{Rc}, \mathrm{Rd}, \mathrm{Rg}_{3}, \mathrm{~F}_{2}$, and $\left.\mathrm{C}-\mathrm{K}\right)$.

was stable at pH 5.0 to 10.0 (Fig. 7A). When the $\mathrm{pH}$ was less than 5.0 or more than 10.0 , the enzyme stability decreased very quickly, and at pH 5.0 and 10.0, the enzyme activity decreased to $38.0 \%$ and $14.0 \%$ of the optimum activity (Fig. 7A). The optimal temperature was found to be $50{ }^{\circ} \mathrm{C}$; at $45{ }^{\circ} \mathrm{C}$, the enzyme had 95.0\% relative activity, while thermo-stability decreased significantly below $45{ }^{\circ} \mathrm{C}$ and no activity was detected when the enzyme was incubated above $50{ }^{\circ} \mathrm{C}$ for $2 \mathrm{~h}$ (Fig. 7B). BglAg-762 was stable below $45{ }^{\circ} \mathrm{C}$, and about $52 \%$ of the activity was lost after incubation at $50{ }^{\circ} \mathrm{C}$ for $2 \mathrm{~h}$. Thus, the optimal temperature for the activity of BglAg-762 was similar to that of the $\beta$-glucosidase isolated from Terrabacter ginsenosidimutans $\left(45^{\circ} \mathrm{C}\right)$ and lower than that of the $\beta$-glucosidase from Pyrococcus furiosus $\left(55{ }^{\circ} \mathrm{C}\right)$. Thus, perhaps BglAg-762 is mesophilic and stable at a neutral $\mathrm{pH}$ range. In addition, the near-neutral optimal $\mathrm{pH}$ and the mild optimal temperature of BglAg-762 are similar to those of ginsenoside-hydrolyzing $\mathrm{GH} 3$ from other bacteria. ${ }^{18,52-55}$ Although the optimum temperature of BglAg-762 against $p$ NPGlc was $50{ }^{\circ} \mathrm{C}$, during extended and stable transformation, the ginsenoside-conversion reaction occurred at $37{ }^{\circ} \mathrm{C}$ with an optimum $\mathrm{pH}$ of 7.0-7.5.

As mentioned in previous sections, heavy metals are atoms with high molecular weights and their concentration may affect enzyme activities. Therefore, the effects of metal ions, EDTA, and $\beta$-mercaptoethanol on the activity of GST-BglAg-762 were investigated. The results were expressed as a percentage of the activity in the absence of the test compound (Table S2 $\dagger$ ). The activity of BglAg-762 was not affected by $1 \mathrm{mM}$ of metal ions $\mathrm{Na}^{+}$, $\mathrm{K}^{+}, \mathrm{Mg}^{2+}, \mathrm{Mn}^{+}$, and $\mathrm{Co}^{2+}$, or EDTA and $\beta$-mercaptoethanol; however, its activity was enhanced by $1 \mathrm{mM} \mathrm{Ca}^{2+}, \mathrm{Co}^{2+}$, and $\mathrm{Mn}^{2+}$. In addition, BglAg-762 activity was decreased by $10 \mathrm{mM}$ of all the tested metal ions (except $\mathrm{Co}^{2+}$ and $\mathrm{Mn}^{2+}$ ), EDTA, and $\beta$ mercaptoethanol. The chelating agent, EDTA (10 mM), inhibited BglAg-762 activity, which indicated that divalent cations 


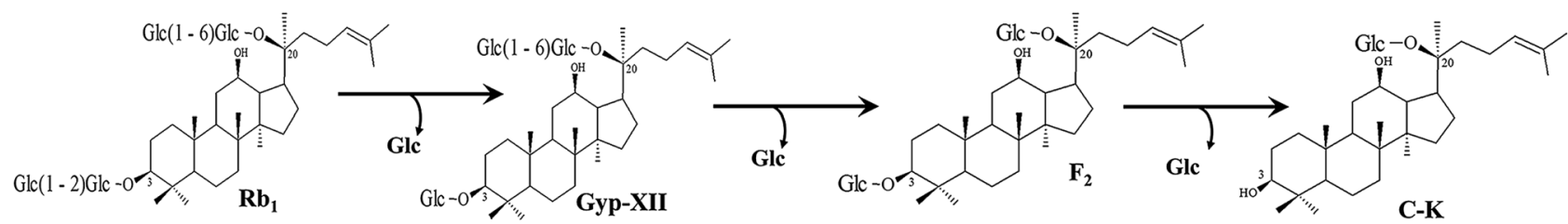

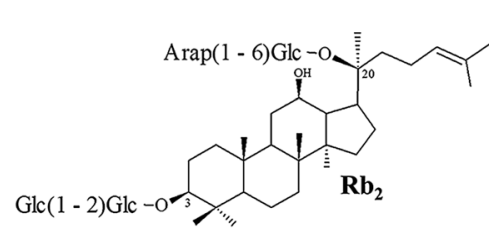
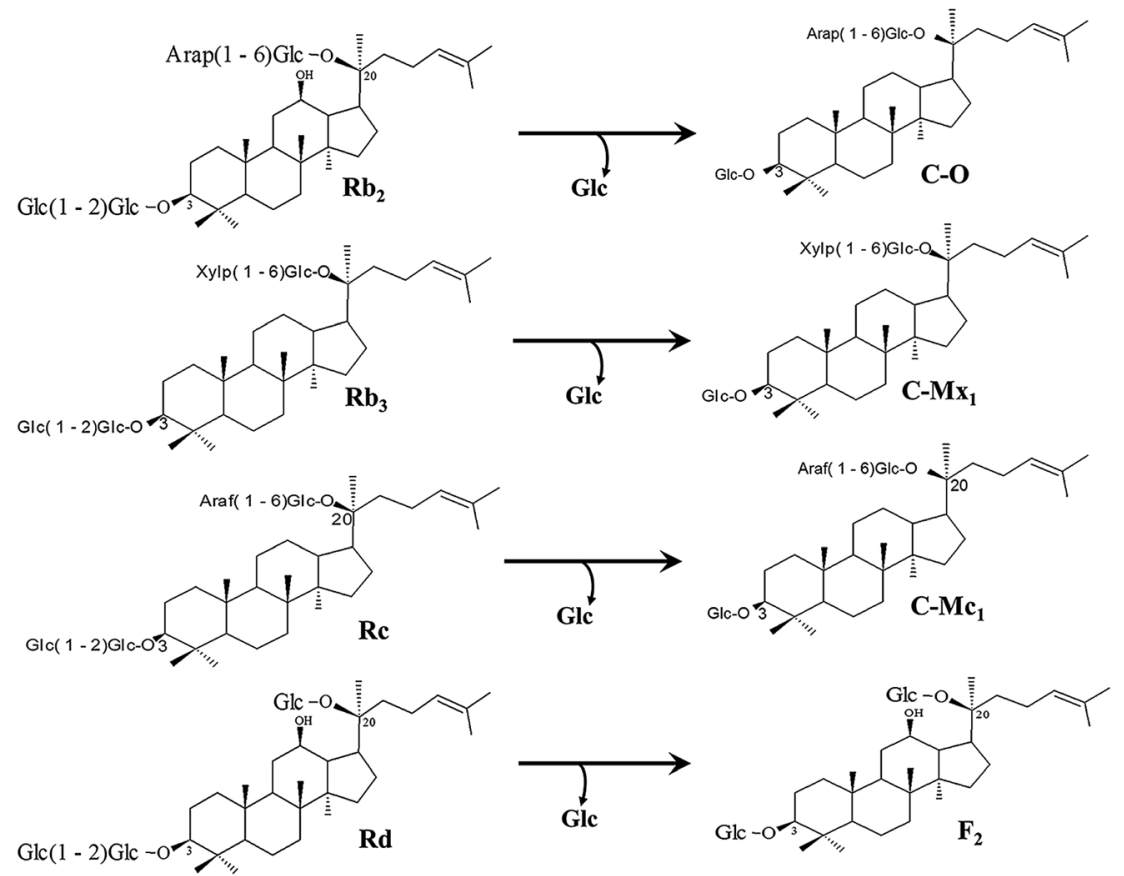

Fig. 6 Pathways for enzymatic biotransformation of ginsenosides $\mathrm{Rb}_{1}, \mathrm{Rb} \mathrm{b}_{2}, \mathrm{R} \mathrm{b}_{3}, \mathrm{Rc}, \mathrm{Rd}$, and Gyp-XVII by recombinant BglAg-762, respectively.

might be required for its activity. However, no dramatic positive effect on the activity of the BglAg-762 was found for any of the tested metal ions.

To investigate the substrate specificity of BglAg-762, it was treated with $\alpha$ - and $\beta$-configurations of $2.0 \mathrm{mM} p \mathrm{NP}$ - and $o \mathrm{NP}$ glycosides. The results, which are summarized in Table 4, showed that BglAg-762 was most active against $p$ NPGlc, followed by $o$ NPGlc, but had no effect on any of the other $p$ NP- and oNP-glycosides.

In this study, we encountered a problem with the sequence similarity through the NCBI protein blast (blastp). Using the data of complete genome sequence of the $\mathrm{BS}^{2} \mathrm{O}^{\mathrm{T}}$ strain, we succeeded in cloning of 17 sets of four (4) different glycoside hydrolases in E. coli. However, when we analyzed the sequence homology, analogy, and paralogy for our functional gene using blastp, the results did not reflect the interesting aspects of the conservation of our target gene. The results of the NCBI blast showed that our gene had a sequence similarity of more than 60 and $70 \%$ to the different glycoside hydrolases (hypothetical proteins), as shown in Table S3.† However, after enzyme expression, most of the enzymes did not show specific activity against a substrate (Table 4), indicating that the corresponding results of blastp for our protein were not accurate and that the hypothetical protein will be considered as a putative, uncharacterized protein.

\subsection{Ginsenoside-transformation characteristics of BglAg- 762}

For verifying the bioconversion pathways of the six PPD-type ginsenosides $\left(\mathrm{Rb}_{1}, \mathrm{Rb}_{2}, \mathrm{Rb}_{3}, \mathrm{Rc}, \mathrm{Rd}\right.$, and Gyp-XVII) by BglAg762, TLC analyses were performed at regular intervals. GSTBglAg-762 was found to transform six ginsenosides, as shown by the $R_{\mathrm{f}}$ values from the TLC analysis (Fig. 5A and B). During the biotransformation of $\mathrm{Rb}_{1}$, two types of metabolites (Gyp-XVII and $\mathrm{F}_{2}$ ) were detected (Fig. $\mathrm{S} 5 \dagger$ ). Thus, BglAg-762 successively hydrolyzed the outer and inner glucose moieties at position C20 and the inner glucose at position C3. It also transformed all PPD-type major ginsenosides into minor ginsenosides within $10 \mathrm{~min}$. During the conversion of all the PPD-type ginsenosides, it was confirmed through transformation pathways that BglAg-762 preferred to hydrolyze glucose moieties at C3, rather than those at C20. From TLC analysis, it was also observed that BglAg-762 could not hydrolyze the PPT-type ginsenosides, Re and $\mathrm{Rg}_{1}$, indicating that BglAg-762 could not hydrolyze single glucose molecules attached to C6 and C20 positions.

The proposed pathways for the biotransformation of ginsenosides by BglAg-762 are as follows: $\mathrm{Rb}_{1} \rightarrow$ Gyp-XVII $\rightarrow \mathrm{F}_{2} \rightarrow$ $\mathrm{C}-\mathrm{k} ; \mathrm{Rb}_{2} \rightarrow \mathrm{C}-\mathrm{O} ; \mathrm{Rb}_{3} \rightarrow \mathrm{C}-\mathrm{Mx}_{1}$; Rc $\rightarrow \mathrm{C}-\mathrm{Mc}_{1}$; Rd $\rightarrow \mathrm{F}_{2}$; and Gyp$\mathrm{XVII} \rightarrow \mathrm{F}_{2}$. The biotransformation occurs through the stepwise hydrolysis of glucose moieties at the C3 and C20 positions of aglycon (Fig. 6). 

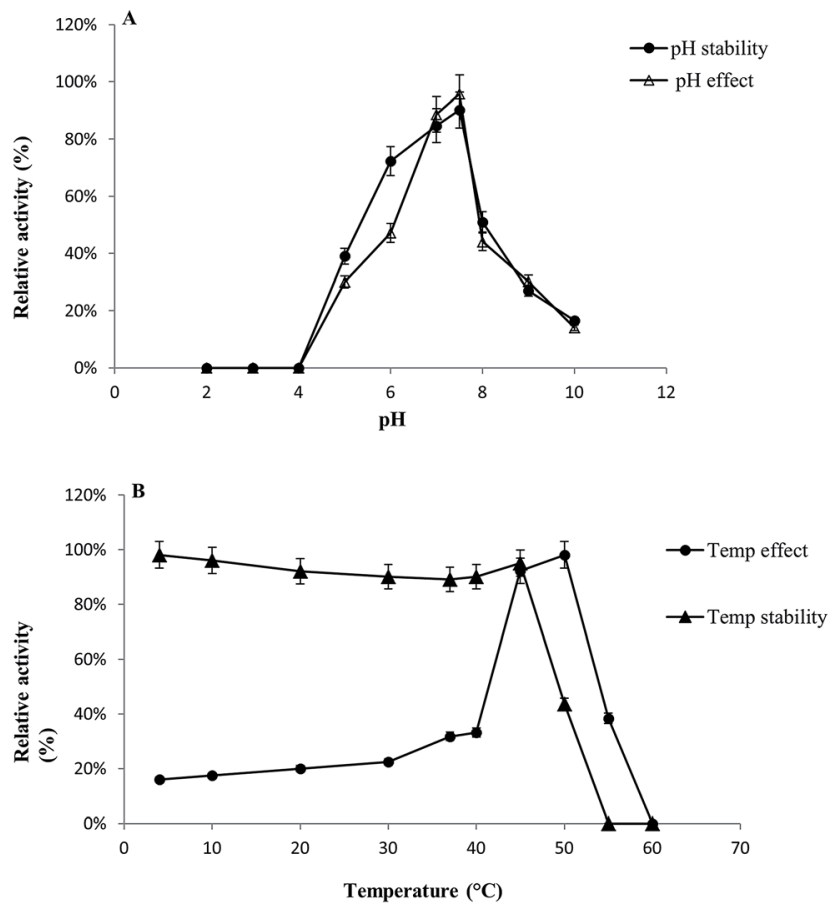

Fig. 7 (A and B) Effect of pH on enzyme activity. The enzyme activities were measured under standard assay conditions. Enzyme solutions containing $2.0 \mathrm{mM}$ pNPGlc were incubated with various buffers at $\mathrm{pH}$ 2.0 to 10.0 for $12 \mathrm{~h}$ at $4{ }^{\circ} \mathrm{C}$. Stability of BglAg-762, the enzymes were incubated for $30 \mathrm{~min}$ at $50{ }^{\circ} \mathrm{C}$ in various buffers at $\mathrm{pH} 2.0$ to 10.0 and the residual activities were measured (A). The effect of temperature on the stability and activity of recombinant BglAg-762 was measured under standard assay conditions. The thermo-dependence of BglAg762 was assayed in $50 \mathrm{mM}$ potassium phosphate buffer $(\mathrm{pH} 7.5)$ at varying temperatures ranging from 4 to $60^{\circ} \mathrm{C}$. Thermostability was tested by incubating aliquots of the enzyme in $50 \mathrm{mM}$ potassium phosphate buffer ( $\mathrm{pH}$ 7.5) for different periods of time at various temperatures. After cooling the sample, residual activity was determined (B).

\section{Conclusion}

Based on the phylogenetic position and phenotypic and chemotaxonomic characteristics, a novel species in the genus Arachidicoccus, isolated from compost, was identified. We proposed $\mathrm{BS}^{\mathrm{T}}{ }^{\mathrm{T}}$ (=KACC $18624^{\mathrm{T}}=\mathrm{LMG} 29195^{\mathrm{T}}$ ) as the type strain of the novels species, Arachidicoccus ginsenosidimutans sp. nov. Complete genome sequencing (GenBank accession number: CP015971) and optical mapping of the strain $\mathrm{BS}^{2} 0^{\mathrm{T}}$ was performed to identify the gene encoding glycoside hydrolase, responsible for ginsenoside transformation. Through complete genome analysis, a novel ginsenoside-transforming $\beta$-glucosidase, termed as BglAg-762, was identified. It belonged to the glycoside hydrolase superfamily 3 . The optimum reaction condition for BglAg-762 was $50{ }^{\circ} \mathrm{C}$ at $\mathrm{pH}$ 7.5. BglAg-762 could convert various major ginsenosides $\left(\mathrm{Rb}_{1}, \mathrm{Rb}_{2}, \mathrm{Rb}_{3}, \mathrm{Rc}, \mathrm{Rd}\right.$, and Gyp-XVII) by selective hydrolysis of glucose moieties. During the conversion of the different PPD-type ginsenosides, BglAg-762 efficiently hydrolyzed the inner glucose moieties at the C3 position. This is the first study to describe this novel species
(Arachidicoccus ginsenosidimutans sp. nov.), to sequence its whole genome, and to characterize a novel ginsenoside-transforming $\beta$ glucosidase (BglAg-762) isolated from it. Furthermore, due to its quick and efficient reaction with the major ginsenoside, $R_{1}$, BglAg-762 might be useful for the mass production of the minor ginsenoside, $\mathrm{F}_{2}$.

\section{Conflicts of interest}

The authors declare that there is no conflict of interest.

\section{Acknowledgements}

This research was supported by the project on survey and excavation of Korean indigenous species of the National Institute of Biological Resources (NIBR) under the Ministry of Environment and by Basic Science Research Program through the National Research Foundation of Korea (NRF) funded by the Ministry of Education (2015R1D1A1A01060255), Republic of Korea. There is no person employed by the funders but support the authors and this research work.

\section{References}

1 I. H. Cho, Effects of Panax ginseng in neurodegenerative diseases, J. Ginseng Res., 2012, 36(4), 342-353.

2 H. J. Park, D. H. Kim, S. J. Park, J. M. Kim and J. H. Ryu, Ginseng in traditional herbal prescriptions, J. Ginseng Res., 2012, 36, 225-241.

3 S. Sengupta, S. A. Toh, L. A. Sellers, J. N. Skepper, P. Koolwijk, H. W. Leung, H. W. Yeung, R. N. Wong, R. Sasisekharan and T. P. Fan, Modulating angiogenesis: The yin and the yang in ginseng, Circulation, 2004, 110, 1219-1225.

4 A. S. Attele, J. A. Wu and C. S. Yuan, Ginseng pharmacology: Multiple constituents and multiple actions, Biol. Pharm. Bull., 1999, 58, 1685-1693.

5 C. S. Yuan, J. A. Wu and J. Osinski, Ginsenoside variability in American ginseng samples, Am. J. Clin. Nutr., 2002, 75, 600601.

6 L. P. Christensen, Ginsenosides chemistry, biosynthesis, analysis, and potential health effects, Adv. Food Nutr. Res., 2009, 55, 1-99.

7 M. A. Tawab, U. Bahr, M. Karas, M. Wurglics and M. Schubert-Zsilavecz, Degradation of ginsenosides in humans after oral administration, Drug Metab. Dispos., 2003, 31(8), 1065-1071.

8 Q. F. Xu, X. L. Fang and D. F. Chen, Pharmacokinetics and bioavailability of ginsenoside $\mathrm{Rb}_{1}$ and $\mathrm{Rg}_{1}$ from Panax notoginseng in rats, J. Ethnopharmacol., 2003, 84, 187-192.

9 T. Akao, M. Kanaoka and K. Kobashi, Appearance of compound $\mathrm{K}$, a major metabolite of ginsenoside $\mathrm{Rb}_{1}$ by intestinal bacterial in rat plasma after oral administrationmeasurement of compound $\mathrm{K}$ by enzyme immunoassay, Biol. Pharm. Bull., 1998, 21, 245e9.

10 M. Z. Siddiqi, M. S. Shafi, K. D. Choi and W. T. Im, Panacibacter ginsenosidivorans gen. nov., sp. nov., with ginsenoside converting activity isolated from soil of 
a ginseng field, Int. J. Syst. Evol. Microbiol., 2016a, 66, 40394045.

11 M. Z. Siddiqi, M. S. Shafi, K. D. Choi and W. T. Im, Sphingobacterium jejuense sp. nov., with ginsenosides converting activity, isolated from compost, Int. J. Syst. Evol. Microbiol., 2016b, 66, 4433-4439.

12 S. R. Ko, K. J. Choi, K. Suzuki and Y. Suzuki, Enzymatic preparation of ginsenosides $\mathrm{Rg}_{2}, \mathrm{Rh}_{1}$, and $\mathrm{F}_{1}$, Chem. Pharm. Bull., 2003, 51(4), 404-408.

13 C. H. Cui, J. K. Kim, S. C. Kim and W. T. Im, Characterization of a ginsenoside-transforming beta-glucosidase from Paenibacillus mucilaginosus and its application for enhanced production of minor ginsenoside $\mathrm{F}(2)$, PLoS One, 2014, 9, e85727.

14 C. H. Cui, S. C. Kim and W. T. Im, Characterization of the ginsenoside-transforming recombinant beta-glucosidase from Actinosynnema mirum and bioconversion of major ginsenosides into minor ginsenosides, Appl. Microbiol. Biotechnol., 2013a, 97, 649-659.

15 J. H. Lee, J. Y. Ahn, T. J. Shin, S. H. Choi, B. H. Lee, S. H. Hwang, J. Kang, H. J. Kim, C. W. Park and S. Y. Nah, Effects of minor ginsenosides, ginsenoside metabolites, and ginsenoside epimers on the growth of Caenorhabditis elegans, J. Ginseng Res., 2011, 35, 375-383.

16 K. W. Leung and A. S. Wong, Pharmacology of ginsenosides: a literature review, Chin. Med., 2010, 5, 20-22.

17 S. Choi, T. W. Kim and S. V. Singh, Ginsenoside $\mathrm{Rh}_{2^{-}}$ mediated G1 phase cell cycle arrest in human breast cancer cells is caused by p15 Ink4B and p27 Kip1dependent inhibition of cyclin-dependent kinases, Pharm. Res., 2009, 26, 2280-2288.

18 S. H. Choi, T. J. Shin, S. H. Hwang, B. H. Lee, J. Kang, J. W. Oh, C. S. Bae, S. H. Lee and S. Y. Nah, Differential effects of ginsenoside metabolites on HERG $\mathrm{k}$ channel currents, J. Ginseng Res., 2011, 35, 191-199.

19 Y. J. Kim, N. Yamabe, P. Choi, J. W. Lee, J. Ham and K. S. Kang, Efficient thermal deglycosylation of ginsenoside $\mathrm{Rd}$ and its contribution to the improved anticancer activity of ginseng, J. Agric. Food Chem., 2013, 61(38), 9185-9191.

20 M. H. Siddiqi, M. Z. Siddiqi, S. Ahn, S. Kang, Y. J. Kim, K. Veerappan, D. U. Yang and D. C. Yang, Stimulative Effect of Ginsenosides $\mathrm{Rg}_{5}: \mathrm{Rk}_{1}$ on Murine Osteoblastic MC3T3-E1 Cells, Phytother. Res., 2014, 28, 1447-1455.

21 M. Z. Siddiqi, M. H. Siddiqi, Y. J. Kim, Y. Jin, M. A. Huq and D. C. Yang, Effect of Fermented Red Ginseng Extract Enriched in Ginsenoside $\mathrm{Rg}_{3}$ on the Differentiation and Mineralization of Preosteoblastic MC3T3-E1 Cells, J. Med. Food, 2015, 18, 1-7.

22 M. Madhaiyan, S. Poonguzhali, M. Senthilkumar, D. Pragatheswari, J. S. Lee and K. C. Lee, Arachidicoccus rhizosphaerae gen. nov., sp. nov., a plant-growth-promoting bacterium in the family Chitinophagaceae isolated from rhizosphere soil, Int. J. Syst. Evol. Microbiol., 2015, 65, 578586.

23 M. Z. Siddiqi, Z. Aslam and W. T. Im, Arachidicoccus ginsenosidivorans sp. nov., with ginsenoside converting activity isolated from ginseng cultivating soil, Int. J. Syst. Evol. Microbiol., 2017, 67, 1005-1010.

24 R. D. Fleischmann, M. D. Adams, O. White, R. A. Clayton, E. F. Kirkness, A. R. Kerlavage, C. J. Bult, J. F. Tomb, B. A. Dougherty and J. M. Merrick, Whole-genome random sequencing and assembly of Haemophilus influenzae Rd, Science, 1995, 269, 496-512.

25 C. M. Fraser, J. D. Gocayne, O. White, M. D. Adams, R. A. Clayton, R. D. Fleischmann, C. J. Bult, A. R. Kerlavage, G. Sutton and J. M. Kelley, The minimal gene complement of Mycoplasma genitalium, Science, 1995, 270, 397-404.

26 W. T. Im, Q. M. Liu, J. E. Yang, M. S. Kim, S. Y. Kim, S. T. Lee and T. H. Yi, Panacagrimonas perspica gen. nov., sp. nov., a novel member of Gammaproteobacteria isolated from soil of a ginseng field, J. Microbiol., 2010, 48, 262-266.

27 O. S. Kim, Y. J. Cho, K. Lee, S. H. Yoon, M. Kim, H. Na, et al., Introducing EzTaxon-e: a prokaryotic 16S rRNA gene sequence database with phylotypes that represent uncultured species, Int. J. Syst. Evol. Microbiol., 2012, 62, 716-721.

28 J. D. Thompson, T. J. Gibson, F. Plewniak, F. Jeanmougin and D. G. Higgins, The CLUSTAL_X windows interface: flexible strategies for multiple sequence alignment aided by quality analysis tools, Nucleic Acids Res., 1997, 25, 48764882.

29 T. A. Hall, BioEdit: a user-friendly biological sequence alignment editor and analysis program for Windows 95/98/ NT, Nucleic Acids Symp. Ser., 1999, 41, 95-98.

$30 \mathrm{M}$. Kimura, The neutral theory of molecular evolution, Cambridge University Press, 1983.

31 N. Saitou and M. Nei, The neighbor-joining method: a new method for reconstructing phylogenetic trees, Mol. Biol. Evol., 1987, 4, 406-425.

32 W. M. Fitch, Toward defining the course of evolution: minimum change for a specific tree topology, Syst. Zool., 1971, 20, 406-416.

33 K. Tamura, G. Stecher, D. Peterson, A. Filipski and S. Kumar, MEGA6: Molecular Evolutionary Genetics Analysis Version 6.0, Mol. Biol. Evol., 2013, 30, 2725-2729.

$34 \mathrm{~J}$. Felsenstein, Confidence limits on phylogenies: an approach using the bootstrap, Evolution, 1985, 39, 783-791.

35 P. Gerhardt, R. G. E. Murray, R. N. Costilow, E. W. Nester, W. A. Woods and N. R. Krieg, et al., Manual of Methods for General Bacteriology, American Society for Microbiology, Washington DC, 1981.

36 J. F. Bernardet, Y. Nakagawa and B. Holmes, Proposed minimal standards for describing new taxa of the family Flavobacteriaceae and emended description of the family, Int. J. Syst. Evol. Microbiol., 2002, 52, 1049-1070.

37 A. Hiraishi, Y. Ueda, J. Ishihara and T. Mori, Comparative lipoquinone analysis of influent sewage and activated sludge by high-performance liquid chromatography and photodiode array detection, J. Gen. Appl. Microbiol., 1996, 42, 457-469.

38 M. Sasser, Identification of bacteria by gas chromatography of cellular fatty acids, USFCC News Lett., 1990, 20, 16. 
39 D. E Minnikin, A. G. O'Donnell, M. Goodfellow, G. Alderson, M. Athalye, et al., An integrated procedure for the extraction of bacterial isoprenoid quinones and polar lipids, $J$. Microbiol. Methods., 1984, 29, 233-241.

40 A. L. Delcher, D. Harmon, S. Kasif, O. White and S. L. Salzberg, Improved microbial gene identification with GLIMMER, Nucleic Acids Res., 1999, 27(23), 4636-4641.

41 R. Overbeek, R. Olson, G. D. Pusch, G. J. Olsen, J. J. Davis, T. Disz, et al., The SEED and the Rapid Annotation of microbial genomes using Subsystems Technology (RAST), Nucleic Acids Res., 2014, 42(Database issue), D206-D214.

42 V. M. Markowitz, K. Mavromatis, N. N. Ivanova, I. M. Chen, K. Chu and N. C. Kyrpides, IMG ER: a system for microbial genome annotation expert review and curation, Bioinformatics, 2009, 25(17), 2271-2278.

43 I. Pagani, K. Liolios, J. Jansson, I. M. a. Chen, T. Smirnova, B. Nosrat, V. M. Markowitz and N. C. Kyrpides, The Genomes OnLine Database (GOLD) v. 4: status of genomic and metagenomic projects and their associated metadata, Nucleic Acids Res., 2012, 40(Database issue), D571-D579.

44 J. Miyake, S. Ochiai-Yanagi, T. Kasumi and T. Takagi, Isolation of a Membrane Protein from $R$. rubrum Chromatophores and Its Abnormal Behavior in SDSPolyacrylamide Gel Electrophoresis Due to a High Binding Capacity for SDS, J. Biochem., 1978, 83, 1679-1686.

45 Q. R. Ahmad, D. H. Nguyen, M. A. Wingerd, G. M. Church and M. A. Steffen, Molecular weight assessment of proteins in total proteome profiles using 1D-PAGE and LC/MS/MS, Proteome Sci., 2005, 3, 6, DOI: 10.1186/1477-5956-3-6.

46 A. Rath, M. Glibowicka, V. G. Nadeau, G. Chen and C. M. Deber, Detergent binding explains anomalous SDSPAGE migration of membrane proteins, Proc. Natl. Acad. Sci. U. S. A., 2009, 106, 1760-1765.

47 G. S. Dotsenko, O. A. Sinitsyna, S. W. Hinz, J. Wery and A. P. Sinitsyn, Characterization of a $\mathrm{GH}$ family 3 betaglycoside hydrolase from Chrysosporium lucknowense and its application to the hydrolysis of beta-glucan and xylan, Bioresour. Technol., 2012, 112, 345-349.

48 A. J. Harvey, M. Hrmova, G. De, J. N. Varghese and G. B. Fincher, Comparative modeling of the threedimensional structures of family 3 glycoside hydrolases, Proteins, 2000, 41, 257-269.

49 B. Henrissat and G. Davies, Structural and sequence-based classification of glycoside hydrolases, Curr. Opin. Struct. Biol., 1997, 7, 637-644.

50 L. Q. Cheng, M. K. Kim, J. W. Lee, Y. J. Lee and D. C. Yang, Conversion of major ginsenoside $\mathrm{Rb}_{1}$ to ginsenoside $\mathrm{F}_{2}$ by Caulobacter leidyia, Biotechnol. Lett., 2006, 28(14), 11211127.

$51 \mathrm{H}$. Chi and G. E. Ji, Transformation of ginsenosides $\mathrm{Rb}_{1}$ and Re from Panax ginseng by food microorganism, Biotechnol. Lett., 2005, 27, 765-771.

52 D. S. An, C. H. Cui, H. G. Lee, L. Wang, S. C. Kim, S. T. Lee, F. Jin, et al., Identification and characterization of a novel Terrabacter ginsenosidimutans sp. nov. $\beta$-glucosidase that transforms ginsenoside $\mathrm{Rb}_{1}$ into the rare gypenosides-XVII and LXXV, Appl. Environ. Microbiol., 2010, 76, 5827-5836.

53 C. H. Cui, Q. M. Liu, J. K. Kim, B. H. Sung, S. G. Kim, S. C. Kim and W. T. Im, Identification and characterization of a Mucilaginibacter sp. strain QM49 beta-glucosidase and its use in the production of the pharmaceutically active minor ginsenosides $(S)-\mathrm{Rh}_{1}$ and $(S)-\mathrm{Rg}_{2}$, Appl. Environ. Microbiol., 2013b, 79, 5788-5798.

54 L. H. Quan, J. W. Min, Y. Jin, C. Wang, Y. J. Kim and D. C. Yang, Enzymatic biotransformation of ginsenoside $\mathrm{Rb}_{1}$ to compound $\mathrm{K}$ by recombinant beta-glucosidase from Microbacterium esteraromaticum, J. Agric. Food Chem., 2012, 60, 3776-3781.

55 C. C. Ruan, H. Zhang, L. X. Zhang, Z. Liu, G. Z. Sun, J. Lei, et al., Biotransformation of ginsenoside $\mathrm{Rf}$ to $\mathrm{Rh}_{1}$ by recombinant beta-glucosidase, Molecules, 2009, 14, 20432048. 